\title{
Disciplining the Americans with Disabilities Act's Direct Threat Defense
}

\author{
Brian S. Prestes $\dagger$
}

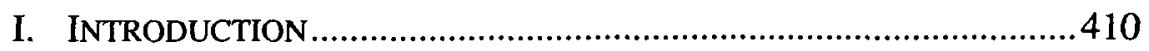

II. THE AMERICANS WITH DISABILITIES ACT AND THE DIRECT THREAT DEFENSE.

A. The ADA's Prohibition on Discrimination Against the

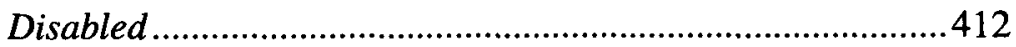

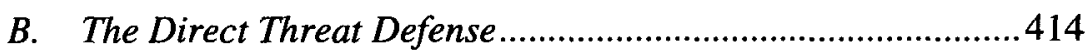

1. Operationalizing Direct Threat ...........................................416

2. Implementing the Balance Envisioned by the ADA ...........416

3. An Insufficiently Guided Inquiry .......................................417

4. The Problem with Unanchored Decision Making ............. 418

III. CURRENT DIRECT ThREAT JURISPRUDENCE: WHEN DOES AN INDIVIDUAL POSE A "SIGNIFICANT RISK"? ......................................422

A. Cases Involving HIV-Positive Disabled Individuals................423

1. Inconsistent Evaluations of HIV .........................................427

2. Inaccurate Assessments of HIV ..........................................428

B. Cases Involving Mentally Ill Disabled Individuals ....................429

1. Inconsistent Evaluations of the Mentally Ill .......................432

2. Inaccurate Assessments of the Mentally Ill ........................435

IV. EXPLANATIONS FOR INCONSISTENT AND INACCURATE DIRECT

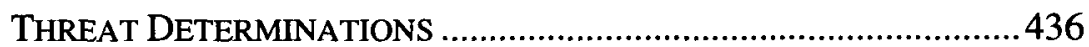

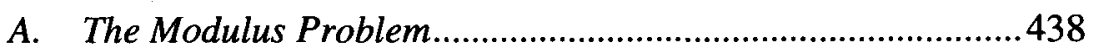

B. Outcome-Dependent Probability Weighting .............................441

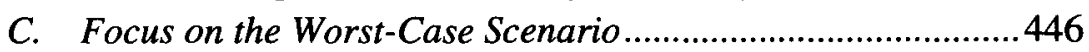

V. Alternative MEANS Of DiRECT ThreAt ANALYSIS ..................448

A. The Text of the ADA Permits Alternatives to the Current Mode of "Direct Threat" Analysis ...........................................448

$\dagger$ B.A. 1997, Wake Forest University; J.D. 2001, University of Chicago. I am especially grateful to Cass Sunstein for extensive comments and assistance in formulating the argument. Thanks also to Michael Edney and Grey Mead for comments and suggestions on an earlier draft. 
B. OSHA's Interpretation of "Significant Risk" 449

C. Statistical Benchmarks Could Improve Direct Threat

Inquiries

1. Statistical Benchmarks and the ADA.

2. Statistical Benchmarks, Consistency, and Accuracy

3. Feasibility of Statistical Benchmarks 458

4. Toward a Comprehensive Decisionmaking Framework .. 460

VI. CONCLUSION 462

I.

\section{INTRODUCTION}

Consider the following three cases: A bus driver employed by a daycare provider for young children suffers from a substantial hearing impairment. ${ }^{1}$ A sales associate at a large department store suffers from a stress related fainting disorder causing her to faint while on the job. ${ }^{2}$ A cruise ship entertainer, living in close quarters with guests and coworkers on the ship, is HIV-positive. ${ }^{3}$ In all three cases the employee is terminated and proceeds to sue the employer for discrimination on the basis of disability. Under the Americans with Disabilities Act of 1990 (ADA), ${ }^{4}$ an employer has a complete defense to disability-based discrimination if it can show that the employee poses a "direct threat to the health or safety of other individuals in the workplace." In which, if any, of the preceding cases does the plaintiff pose a direct threat? Left to one's own rules of thumb, it is difficult to determine the correct answer. Without additional guidelines for what constitutes a direct threat, readers are likely to form inconsistent and inaccurate conclusions regarding these three "hypothetical" plaintiffs.

Similarly, juries, left to their own devices and ambiguous statutory commands, are likely to produce inconsistent and inaccurate results. When

1. These facts were taken from Rizzo v. Children's World Learning Centers, Inc, 173 F.3d 254, 257-58 (5th Cir. 1999), which upheld the jury's finding that the plaintiff did not pose a direct threat because there was no empirical evidence in the record of any problems associated with the plaintiff driving the van. $I d$. at 260 .

2. These facts were taken from Nunes v. Wal-Mart Stores, Inc., 164 F.3d 1243 (9th Cir. 1999), which reversed the district court's grant of summary judgment in favor of the defendant. Id. at 1245, 1249.

3. These facts are similar to those in EEOC v. Dolphin Cruise Line, 945 F. Supp. 1550 (S.D. Fla. 1996), which held that the plaintiff-employee did not pose a direct threat to others.

4. Pub. L. No. 101-336, 104 Stat. 327, codified at 42 U.S.C. $\S \S 12101-12213$ (1994).

5. 42 U.S.C. $\$ 12113$ (b). For a general discussion of the ADA's direct threat defense, see DAVID K. Fram, Resolving ADA WorkPlace Questions: How CoURtS and ENFORCEMENT AGENCIES ARe Dealing WITH EVolving EMPLOYMENT ISSUES ch. 4 (7th ed. 1999); RoBERT L. BuRGDORF, JR., DISABILITY DISCRIMINATION IN EMPLOYMENT LAW 249-70 (1995). 
direct threat determinations are unguided, and therefore inaccurate and inconsistent, the ADA falls short of its anti-discriminatory purpose and serious social harms result: Some disabled individuals are wrongfully barred from the workplace and suffer all of the harms accompanying denial of employment, while others are mistakenly permitted to work, resulting in potentially catastrophic workplace injuries.

This Article addresses the potential for "statistical benchmarks" to improve the consistency and accuracy of direct threat determinations under the ADA. The Article makes a descriptive point that current direct threat determinations are both inconsistent and inaccurate. The Article then argues that the Equal Employment Opportunity Commission (EEOC) should adopt explicit numerical benchmarks to serve as a guide for when a risk is sufficiently large to be considered "significant." Statistical benchmarks would improve the consistency and accuracy of direct threat determinations by providing a "modulus" by which to measure whether a risk is clearly significant, clearly insignificant, or somewhere in between. These benchmarks would better discipline the direct threat decision making process, resulting in more consistent and accurate dispositions.

A more disciplined method for determining whether a risk is significant would better align direct threat determinations with the balance envisioned by the ADA generally and the direct threat defense in particular. $^{8}$ Statistical benchmarks could improve the quality of direct threat decisions by serving as anchors to help decision makers ${ }^{9}$ more consistently and accurately determine whether a given risk is large enough to constitute a significant risk or small enough to constitute an insignificant risk. Although the significant risk inquiry logically includes an evaluation of at least two variables - probability (the likelihood of the harm occurring) and outcome (the magnitude of the potential harm)-numerical benchmarks for significance have the potential to improve the overall accuracy of the decision. ${ }^{10}$

6. For the purposes of this Article, the term "statistical benchmark" refers to a numerical pole (or set of poles) that establishes a standard by which to measure whether a risk is significant.

7. See infra note 155 and accompanying text.

8. See infra Part II.B and note 24 in particular.

9. The Article refers to "decision makers" as a catch-all to capture the range of parties assessing whether a disabled individual poses a direct threat. These parties include EEOC lawyers, judges, juries, private attorneys, and potential plaintiffs and defendants. In some instances, the Article refers to juries, in particular, because juries make the direct threat determination at trial, see infra note 23, and because juries are uniquely prone to the errors outlined in Part IV. Statistical benchmarks, however, would be helpful in whatever context the direct threat determination is made.

10. The significant risk determination requires an analysis of both probability and outcome. This discussion focuses on the effectiveness of statistical benchmarks in disciplining the probability inquiry because decision makers are more likely to err in the probability part of the inquiry and because the concept of quality-adjusted life years, see supra notes 250-58 and accompanying text, allows decision makers to hold end state constant thereby facilitating a direct comparison of probability assessments. 
Part II describes the ADA's prohibition on discrimination and the direct threat defense. Part III analyzes existing case law to determine what constitutes a direct threat under the ADA. This Part makes the descriptive claim that direct threat determinations are inconsistent and possibly inaccurate. Part IV offers some explanations for inconsistent direct threat determinations. These explanations suggest the reforms most likely to ameliorate the effects of undisciplined inquiries under existing doctrine. Finally, Part $\mathrm{V}$ discusses alternatives to the current undisciplined inquiry and proposes that courts use statistical benchmarks, similar to those used in the Occupational Safety and Health Administration's (OSHA) interpretation of "significant risk," 11 to determine whether an individual poses a direct threat. ${ }^{12}$ Using numerical benchmarks to distinguish significant risks from insignificant risks would improve the consistency and accuracy of the currently ineffective risk assessment framework.

II.

\section{THE AMERICANS WITH DisABILITIES ACT AND THE DIRECT THREAT DEFENSE}

\section{A. The ADA's Prohibition on Discrimination Against the Disabled}

The Americans with Disabilities $\mathrm{Act}^{13}$ is the "first comprehensive federal law to prohibit discrimination in employment against the estimated 43 million Americans with physical or mental disabilities." 14 The ADA prohibits a "covered entity"15 from "discriminat[ing] against a qualified individual with a disability because of the disability of such individual."16

11. See infra Part V.B.

12. This Part addresses two separate but related questions. First, does society have sufficient information to reduce the multivariable "significant risk" inquiry down to numbers in which we can have much confidence? In other words, are statistical benchmarks feasible? Second, assuming we can generate relatively accurate numbers, should we sort significant from insignificant risks based on statistical benchmarks? The Article focuses on the latter question without ignoring the former.

13. 42 U.S.C. $\$ \$ 12101-12213$.

14. Mark A. Rothstein et Al., Employment Law 186 (1994); see Paul Steven Miller, The Evolving ADA, in EMPLOYMENT, DISABILITY, AND THE AMERICANS WITH DISABILITIES ACT: ISSUES IN LAw, PUBLIC POLICY, AND RESEARCH 3 (Peter David Blanck ed., 2000) (claiming that "[t]he passage of the Americans with Disabilities Act of 1990 (ADA) marked a victory in the ongoing struggle of over 49 million people with disabilities to overcome the barriers which prevent their full participation in society"). The field of disability rights law has "undergone an exponential burst of expansion. . . . Most notably, enactment of the Americans With Disabilities Act (ADA) in 1990 has changed the landscape of the disability rights field." BURGDORF, supra note 5, at vii.

15. 42 U.S.C. $\S 12112(a)$.

16. 42 U.S.C. $\S 12112$ (a). Although this Article focuses on the employment provisions of the ADA (Title 1), the ADA also addresses discrimination regarding public services (Title II), discrimination against the disabled in public accommodations (Title III), and obligations of common carriers providing telephone service to hearing- and speech-impaired individuals (Title IV). For a general discussion of the 
To prevail under the ADA, a plaintiff must prove that (1) she has a disability, (2) she is qualified, and (3) she was discriminated against because of her disability. ${ }^{17}$

Although, at first cut, such a showing does not seem particularly burdensome, "courts are often construing the ADA far too narrowly and excluding from its protection many victims of real disability discrimination." 18 In fact, "A recent study done by the American Bar Association found that employers win most disability employment discrimination lawsuits. The study found that employers won 92 percent of ADA Title I cases filed." 19

Numerous decision makers are potentially involved in assessing the viability of a claim under Title I of the ADA. Initially, individuals seeking to enforce rights granted by the ADA must file with the regional office of the EEOC. The EEOC, having received a complaint, must investigate charges and "[i]f the Commission determines after such investigation that there is reasonable cause to believe that the charge is true, the Commission shall endeavor to eliminate any such alleged unlawful employment practice by informal methods of conference, conciliation, and persuasion." ${ }^{20}$ If conciliation fails, the EEOC may bring suit against the private employer. ${ }^{21}$ Should the EEOC choose not to bring charges, the aggrieved party may pursue a private action in court. Once in court, the determination of whether the plaintiff has proved her prima facie discrimination case and whether the defendant has successfully advanced any affirmative defense to such discrimination is generally a question for the jury. ${ }^{22}$ The direct threat defense is no exception: whether a plaintiff poses a direct threat is a question of fact to be determined by the jury. ${ }^{23}$

broad outline of the ADA, see ROTHSTEIN ET AL., supra note 14, at 186-90.

17. 42 U.S.C. § 12112(a); see, e.g., Rizzo v. Children's World Learning Ctrs., Inc., 173 F.3d 254, 260 (5th Cir. 1999).

18. Miller, supra note 14 , at 7 .

19. Id. at 13 n. 19.

20. 42 U.S.C. $\& 2000 \mathrm{e}-5(\mathrm{~b})$.

21. The EEOC, a five-person commission appointed by the President, has an Office of General Counsel to litigate on behalf of the Commission.

22. See, e.g., Hamlin v. Township of Flint, 165 F.3d 426, 432 (6th Cir. 1999) (noting that "the district court correctly found that a genuine issue of material fact existed on this point [regarding whether the plaintiff posed a direct threat under the ADA] that required submission to a jury").

23. See, e.g., Rizzo v. Children's World Learning Ctrs., Inc., 84 F.3d 758, 764 (5th Cir. 1996) (holding that, where plaintiff-bus driver is hearing impaired and disputes her ability to hear a choking child, whether plaintiff poses a direct threat is a question of fact making summary judgment "inappropriate"); see also Lawrence H. Clore, Robin W. Coopwood \& Shelly A. Leibham, Survey: Labor \& Employment Law, 28 TEXAS TECH. L. REV. 639, 658 (1997) (stating that "[d]etermining whether an individual is a direct threat is a question of fact"). But see Bradley v. University of Texas M.D. Anderson Cancer Ctr., 3 F.3d 922, 924 (5th Cir. 1993) (per curiam) (upholding a district court's summary judgment in favor of the defendant-hospital on the issue of whether the plaintiff, an HIVpositive surgical technician, posed a direct threat). 


\section{B. The Direct Threat Defense}

The ADA does not absolutely prohibit discrimination: it requires balancing the benefit of allowing the disabled to work against the harm disabled employees might cause to third parties. One defense to alleged discrimination under the ADA, that serves as an example of this balancing requirement, is that the plaintiff would pose a "direct threat to the health or safety of other individuals in the workplace." ${ }^{24}$ By importing the phrase "direct threat" into the ADA, Congress intended to codify ${ }^{25}$ the interpretation of the Rehabilitation Act's direct threat defense ${ }^{26}$ first articulated in School Board of Nassau County v. Arline. ${ }^{27}$

The ADA defines "direct threat" as "a significant risk to the health or

The text of the ADA provides for a right to jury trial generally, incorporating by reference "[t]he powers, remedies, and procedures set forth in sections 705, 706, 707, 709, and 710 of the Civil Rights Act of 1964." 42 U.S.C. $§ 12117$ (1994); see Henry H. Drummonds, The Sister Sovereign States: Preemption and the Second Twentieth Century Revolution in the Law of the American Workplace, 62 FORDHAM L. REV. 469, 595 (1993) (stating that "newly established availability of jury trials and damages in federal Title VII and ADA cases threatens to accelerate the tend of increasing verdicts in employment litigation"); Thomas P. Murphy, Disabilities Discrimination Under the Americans with Disabilities Act, 36 CATHOLIC LAW. 13, 15 (1995) (stating that "[e]mployers should be particularly aware of the remedies available under Title I of the ADA. Unlike other provisions of the ADA, Title I provides for a jury trial."); Karen Dill Danforth, Note, Reading Reasonableness out of the ADA: Responding to Threats by Employees with Mental Illness Following Palmer, 85 VA. L. REV. 661, 694 (1999) (noting that "[d]eterminations of whether someone poses a direct threat" are a "quiestion of fact" not a "matter[] of law").

24. 42 U.S.C. $\S 12113$ (a)-(b). "Th[e] 'direct threat' defense attempts to balance employers' legitimate efforts to ensure safe working conditions with the rights of individuals with disabilities not to be disqualified from jobs because of unfounded fears that they pose increased health or safety risks in the workplace." BURGDORF, supra note 5, at 249.

25. See H.R. REP. No. 101-485(II), at 56-57 (1990), reprinted in 1990 U.S.C.C.A.N. 303, 338-39 (expressing congressional intent to codify the direct threat defense as established under the Rehabilitation Act); H.R. REP. No. 101-485(III), at 45 (1990), reprinted in 1990 U.S.C.C.A.N. 445, 468 (same).

26. 29 U.S.C. $\$ 794$ (1994). The Rehabilitation Act contains a direct threat defense. Section 504 of the Rehabilitation Act prohibits discrimination against "otherwise qualified individual[s] with a disability." 29 U.S.C. $\$$ 794(a). A qualified individual with a disability does not include an "individual who has a currently contagious disease or infection and who ... would constitute a direct threat to the health or safety of other[s]." 29 U.S.C. $§ 705(20)(D)$ (emphasis added). "[I]nterpretations of the ADA are guided by Rehabilitation Act precedent." Nunes v. Wal-Mart Stores, Inc., 164 F.3d 1243, 1248 n.2 (9th Cir. 1999); see Yin v. California, 95 F.3d 864, 867 (9th Cir. 1996); Danforth, Note, supra note 23, at 663 (stating that "the majority of case law on disability discrimination thus far has involved the Rehabilitation Act"). For a general discussion of the relationship between the ADA's direct threat defense and the Rehabilitation Act, see BURGDORF, supra note 5, at 252 ("The principle that an individual must be able to work safely to be considered a 'qualified individual with a disability' is derived from case law interpreting the Rehabilitation Act of 1973.").

27. 480 U.S. $273,276,284,287$ (1987) (holding that the plaintiff, a school teacher infected with tuberculosis, was unqualified for her job only if she posed a significant risk to others in the workplace). The "basic factors" used in Arline to determine whether the plaintiff posed a direct threat are the basis for the four-factor significant risk inquiry currently mandated by the EEOC. See infra note 38 and accompanying text. 
safety of others that cannot be eliminated by reasonable accommodation." ${ }^{28}$ Mere existence of a risk is insufficient to constitute a direct threat, rather, the risk must be significant. ${ }^{29}$ "[A]n employer ... is not permitted to deny an employment opportunity to an individual with a disability merely because of a slightly increased risk. The risk can only be considered when it poses a significant risk, i.e., high probability of substantial harm; a speculative or remote risk is insufficient." ${ }^{30}$

The direct threat defense most often surfaces when employers mandate certain health or safety standards governing employees. "These standards may range from general requirements designed to ensure overall workplace safety to specific requirements intended to reduce certain hazards or to prevent particular types of injuries." ${ }^{31}$ When these standards tend to screen out the disabled, employers may successfully invoke the defense so long as the standards screen out only those individuals posing a direct threat to the health or safety of others.

In a direct threat inquiry, decision makers must determine whether a plaintiff poses a significant risk, and, if so, whether the risk could be reduced or eliminated by reasonable accommodations. ${ }^{32}$ Whether a plaintiff is ultimately deemed to pose a significant risk is assessed based on the risk posed by the plaintiff after the employer has made the reasonable accommodations required by the ADA.${ }^{33}$ This Article addresses those risks that cannot be eliminated by reasonable accommodation..$^{34}$ In order to focus on the direct threat inquiry, this Article assumes that employers have made all reasonable accommodations and assesses the risk from that standpoint, as mandated by the statute. ${ }^{35}$ This assumption focuses the inquiry on a

28. 42 U.S.C. $\$ 12111$ (3) (emphasis added). The Article refers to both "direct threat" and "significant risk" when discussing the inquiry mandated by the ADA. Because the text of the ADA defines "direct threat" as a "significant risk," $i d$., the direct threat inquiry always requires consideration of whether the individual poses a significant risk.

29. See Arline, 480 U.S. at 287 \& n.16; Hamlin v. Township of Flint, 165 F.3d 426, 432 (6th Cir. 1999) (holding that "speculative" risk is insufficient to pose a direct threat), quoting 29 C.F.R. $\$$ 1630.2(r); see also Bragdon v. Abbott, 524 U.S. 624, 649 (1998) (noting that "few, if any, activities in life are risk free").

30. 29 C.F.R. $\S 1630.2$ (r) app. (emphasis added).

31. BURGDORF, supra note 5 , at 249.

32. 42 U.S.C. $\$ 12111$ (3) (defining "direct threat" as "a significant risk ... that cannot be eliminated by reasonable accommodation"); see, e.g., Bay Area Addiction Research \& Treatment, Inc. v. City of Antioch, 179 F.3d 725, 736 (9th Cir. 1999) ("The court must first determine whether an individual poses a significant risk. If he does, the court must then ask whether there is a reasonable modification that would counteract the risk.").

33. 42 U.S.C. $\S 12111(3)$.

34. Once it is determined that a reasonable accommodation can wholly eliminate a risk, the direct threat defense is no longer in play; definitionally, an individual does not pose a direct threat if a reasonable accommodation can sufficiently reduce or eliminate the risk.

35. 42 U.S.C. $\$ 12111$ (3) (defining "direct threat" as "a significant risk ... that cannot be eliminated by reasonable accommodation"). 
comparison of risks posed by the disabled in the workplace by holding the "reasonable accommodation" (cost of risk reduction) variable constant.

\section{Operationalizing Direct Threat}

The EEOC is responsible for promulgating regulations to implement Title $I$ of the $\mathrm{ADA}^{36}$ EEOC regulations implementing the equal employment provisions of the ADA define "direct threat," in relevant part, as "a significant risk of substantial harm to the health or safety of the individual or others that cannot be eliminated or reduced by reasonable accommodation." ${ }^{37}$ Relevant factors include: "(1) The duration of the risk; (2) The nature and severity of the potential harm; (3) The likelihood that the potential harm will occur; and (4) The imminence of the potential harm." 38 Some courts, focusing on the probability element of the inquiry, as opposed to the potential harm, have held that for a risk to be significant, it must be "highly probable," not simply "more likely." 39

Although the EEOC's definition of direct threat specifies four relevant factors, including likelihood that the potential harm will occur, it does not specify an exact probability that presumptively renders any risk significant or insignificant. In contrast to the ADA's multifactor balancing test, OSHA applies a numerical floor and ceiling for what counts as a significant risk under the Occupational Safety and Health Act. Because the OSHA comparison will be developed in greater depth in Part V, it is sufficient at this point to suggest that numerical benchmarks help discipline OSHA's inquiry. If similar benchmarks were considered in the ADA context more consistent and accurate decisions would result.

\section{Implementing the Balance Envisioned by the ADA}

The ADA's prohibition on discrimination yields several benefits from integrating the disabled into the workforce. Employment of the disabled

36. 42 U.S.C. $\$ 12101$; ROTHSTEIN ET AL., supra note 14, at 190.

37. 29 C.F.R. $\$ 1630.2(\mathrm{r})$.

38. 29 C.F.R. $\$ 1630.2(r)$; see Sch. Bd. of Nassau County v. Arline, 480 U.S. 273, 288 (1987) (articulating a similar test).

39. See, e.g., Hamlin v. Township of Flint, 165 F.3d 426, 432 (6th Cir. 1999) (quoting 29 C.F.R. $\S$ $1630.2(r)$ stating that "an employer ... is not permitted to deny an employment opportunity to an individual with a disability merely because of a slightly increased risk"); EEOC v. Kinney Shoe Corp., 917 F. Supp. 419 (W.D. Va. 1996), aff d sub nom. Martinson v. Kinney Shoe Corp., 104 F.3d 683 (4th Cir. 1997). But see Onishea v. Hopper, 171 F.3d 1289, 1299 (11th Cir. 1999) (holding that a "theoretically possible method of transmission" is significant in the context of an HIV-positive prisoner). 
reduces welfare rolls ${ }^{40}$ harnesses the productivity of added members of the workforce, and advances the normative goal of refusing to convert morally irrelevant differences ("disabilities") into disadvantages. ${ }^{41}$ The direct threat defense attempts to balance the advancement of these goals against the risk of harm to third parties-for example, coworkers or customers in the workplace who could be harmed by a disabled employee - by mandating nondiscriminatory hiring practices except in circumstances where employment of the disabled would pose a significant risk to others.

By accounting for both the benefits and the costs of employing the disabled, the ADA makes an explicit judgment that, at some point, the need to protect others trumps the disabled individual's right to work. ${ }^{42}$ "Recognizing that the need to protect public health may at times outweigh the rights of disabled individuals, Congress created a narrow exception to [the ADA's] broad prohibition against discrimination." ${ }^{43}$ The direct threat defense is unique from the other statutory balancing provisions because it expressly evaluates costs imposed on third parties. When employment of the disabled individual poses a significant risk to others, as opposed to mere inconvenience or reduced profits, the ADA permits employers to discriminate.

No matter where the statute draws the line between acceptable and unacceptable risks posed by the disabled, the argument for disciplining the direct threat inquiry rests on a descriptive claim that the ADA does strike some balance. The modest claim is that the law should provide better guidance to decision makers attempting to implement the balance and that statistics would advance this goal.

\section{An Insufficiently Guided Inquiry}

It is unclear when a risk is "significant" enough to render what would otherwise constitute discrimination a lawful refusal to bear an unreasonably high risk. The text of the ADA and relevant regulations provide decision makers little guidance. Although the EEOC regulations list factors relevant

40. The problem of unemployment is particularly acute for those suffering from psychiatric disabilities. For instance, "[t]he National Institute of Mental Health estimated that there are over 3 million adults aged 18 to 69 who have a serious mental illness, of whom $70-90$ percent are unemployed. There has been an enormous growth in the social security rolls; over the last ten years, this nation has spent $\$ 72$ billion on cash assistance for people with mental illness." Miller, supra note 14 , at $12 \mathrm{n} .7$.

41. See id. at 11 (noting that "[t]he ADA and the principles in it represent an important paradigm policy shift .... No longer does the law exclude a disabled person because there is something 'wrong' with him or her. Rather, the law recognizes that inherent in the physical environment . . are bigotries, myths, and fears.").

42. See supra note 24 and accompanying text.

43. Montalvo v. Radcliffe, 167 F.3d 873, 876 (4th Cir. 1999) (describing the direct threat defense under Title III of the ADA, which applies to public accommodations). 
to determining a risk's significance, ${ }^{44}$ neither the text of the ADA nor regulations provide an explicit numerical benchmark for what constitutes a significant risk. Courts determining whether a plaintiff is a significant risk must engage in an individualized inquiry based on "objective, scientific information." 45 Juries deciding whether a plaintiff has presented "objective, scientific" evidence lack meaningful statutory or regulatory guidance.

This is not to say that there is a drought of evidence concerning the numerous potential risks and harms posed by a wide array of disabilities. Doctors, psychologists, statisticians, and insurance companies have amassed a wealth of data and the availability and accuracy of this data will continue to increase. ${ }^{46}$ The data, however, cannot a priori sort plaintiffs between the categories of significant and insignificant risk absent a more precise definition of what a "significant risk" is.

\section{The Problem with Unanchored Decision Making}

Absent an explicit set of benchmarks, decision makers will perform risk calculations implicitly, by way of ad hoc determinations about what constitutes a "significant risk" given the facts of the specific case. ${ }^{47}$ Unanchored determinations, resulting from insufficient guidance, may

44. See supra note 38 and accompanying text.

45. Bragdon v. Abbott, 524 U.S. 624, 649 (1998); see 29 C.F.R. \$ 1630.2(r) ("The determination that an individual poses a 'direct threat' shall be based on an individualized assessment of the individual's present ability to safely perform the essential functions of the job. This assessment shall be based on a reasonable medical judgment that relies on the most current medical knowledge and/or on the best available objective evidence."). An individualized assessment may be unnecessary, however, if such an assessment is impossible. See, e.g., EEOC v. Exxon Corp., 967 F. Supp. 208 (N.D. Tex. 1997) (holding that impracticability of determining risk and impact of relapse justifies employer's failure to perform individualized inquiry into whether former addicts pose a direct threat). Likewise, an employer's qualification standard that does not target a particular individual, but, rather, exists across the board, can be justified as a "business necessity" without a specific inquiry into the particular circumstances surrounding a given employee. EEOC v. Exxon Corp., 203 F.3d 871, 2000 U.S. App. LEXIS 1886, *12 (5th Cir. 2000).

46. In a recent Paper, Professors Meadow and Sunstein argue that "[f]or the first time, it is becoming possible for law to rely on [statistical data], precisely because such evidence is becoming increasingly available." William Meadow \& Cass R. Sunstein, Statistics, Not Experts, Chicago John M. Olin Law \& Economics Working Paper No. 109 (2d series) (preliminary draft, Nov. 20, 2000), available at http://papers.ssm.com/paper.taf?abstract_id=252824 (visited Feb. 26, 2001). In the context of their discussion of statistical data concerning the standard of care in medical malpractice cases, Meadow and Sunstein note that "[u]ntil recently, the legal system has been unable to rely on statistical data for the simple reason that it has not existed. But it is increasingly common to develop data sets about physician choices and behavior, and the legal system will have an increasingly large amount of information on which to draw." Id.

47. The dissent in Rizzo v. Children's World Learning Ctrs., Inc., 173 F.3d 254, 269 (5th Cir. 1999) (Wiener dissenting), is a good example of the ad hoc balancing approach. In Rizzo, the dissent held that "[an] employer must always act reasonably under the circumstances" when deciding whether to remove an employee from a duty because they pose a direct threat. $I d$. The dissent described the direct threat inquiry as "a fact-intensive inquiry that must be determined on a case-by-case basis." Id. 
result in inconsistency and incoherence. Poorly guided decisions may also cause errors in both directions-mistaken findings of direct threat ("false positives") as well as mistaken findings of no direct threat ("false negatives"). Inconsistency and errors have significant consequences.

Consistent direct threat determinations are important. ${ }^{48}$ First, consistency is a good proxy for accuracy. If decisions are all over the map, then it is reasonable to assume that at least some of them are incorrect. Beyond serving as a proxy, consistent direct threat decision making is valuable for at least two other reasons: fairness ${ }^{49}$ and efficiency. ${ }^{50}$ As a matter of fairness, consistency is required in order to ensure that the similarly situated receive similar treatment. If efficiency is our concern, then consistency is valuable because it facilitates avoidance of unintended violations of the law and settlement of legal disputes. Finally, consistency is important as a matter of coherence. ${ }^{51}$ The internal contradictions and temporal instability inherent in an inconsistent framework call the framework's legitimacy, credibility, and rationality into question..$^{52}$

Accurate direct threat decisions are also important. Accuracy can be measured in terms of whether the employee barred from the workplace (or allowed to work) poses an empirically valid risk as opposed to an imagined or illusory one. In other words, correct determinations accurately sort individuals into the direct threat category if and only if those individuals

48. Whether direct threat determinations are consistent is a separate, yet related, question from whether they are accurate. Analytically, it is important to separate the inconsistency claim from the accuracy claim-decision makers could be extremely consistent and still be inaccurate; in other words, they could be consistently wrong.

49. Use of consistency as a measure of "good" decisions makes sense if we value faimess; erratic decisions form a reasonable basis for the normative claim that status quo judgments are "bad" or "wrong" because such judgments treat similarly situated disabled individuals differently. For a similar argument, made in the punitive damages context see Cass R. Sunstein, Daniel Kahneman \& David Schkade, Assessing Punitive Damages (with Notes on Cognition and Valuation in Law), 107 YALE L.J. 2071, 2077 (1998) ("It is not difficult to understand the widespread concern with erratic punitive damage awards. If similarly situated people-plaintiffs and defendants alike-are not treated similarly, erratic awards are unfair. As a matter of faimess, the evidence suggests that some awards are too low, while others are too high.").

50. Unpredictable direct threat determinations will result in parties wasting resources in litigation and courts wasting resources trying to apply a multi-factor balancing test that yields no clear answer. Additionally, uncertainty may result in underprotection or overprotection of employee safety by employers as they struggle to avoid an unnecessarily ambiguous threshold for liability. See Sunstein, Kahneman \& Schkade, supra note 49, at 2077 (noting, in the context of unpredictable punitive damage awards by juries, that "resources are likely to be wasted on that calculation, and as a practical matter, a risk of extremely high awards is likely to produce excessive caution in risk-averse managers and companies."); David Schkade, Cass R. Sunstein \& Daniel Kahneman, Deliberating About Dollars: The Severity Shift, 100 CoLuM. L. REv. 1139, 1168 (2000) (noting that unpredictability "may produce overdeterrence in risk-averse defendants").

51. See also RONALD DWORKIN, LAW's EMPIRE 184 (1986) (stating that "it is inconsistency in principle among the acts of the state personified that integrity condemns").

52. See LON FUller, The MORAlity OF LAW (1960); DwORKIN, supra note 51. 
pose a risk to others that is objectively significant. Accurate decisions will exclude high-risk individuals from some workplaces and permit low-risk individuals to work.

The value of accurate direct threat decisions is rather intuitive. "Perhaps the most obvious purpose of the trial system is to reach accurate verdicts.... Apart from any practical benefits of deciding cases accurately ... the accuracy of verdicts has moral implications." 53 Accurate direct threat determinations are critical to carrying out the directive of the ADA: these decisions will affect the lives of real people so it is important that these decisions be made prudently.

Beyond the antidiscriminatory aim of the ADA, a rational response to the risks posed by the disabled in the workplace is critical to allocating our risk reduction dollars wisely. "In a world of finite resources we can only protect ourselves from so many things. If we overspend on [low] risks ... we have less to spend on greater threats." ${ }^{54}$ For instance, a tendency to find inaccurately that employees with certain feared disabilities such as HIV or mental illness pose an unacceptable risk, combined with a tendency to find that other categories of employees pose an insignificant risk when in fact it is substantial, will result in a misallocation of risk reduction resources. As a result, people will be injured or killed on the job because employees posing a danger will be permitted to work while others will be prevented from working because they are mistakenly found to pose a direct threat.

Erroneous direct threat determinations result in errors in two directions-false positives and false negatives. False positives harm particular classes of disabled individuals. We should expect decision makers, given relatively free reign to impose their judgments of significant risk, to find some disabilities to pose more of a risk than others based on subjective and unfounded fears, misbeliefs, and prejudices attached to certain disabilities. ${ }^{55}$ Disabled individuals, subject to these fears and prejudices, are harmed when they are excluded from the workplace based on mistaken findings that they pose a direct threat to others. Decision makers, placing too much weight on the potential harm of employing the disabled and too little weight on the more abstract benefit of including the disabled in the workplace, may produce inaccurate decisions that conflict with the ADA's antidiscriminatory purpose ${ }^{56}$ and the policy goal of rational

53. Daniel Shaviro, Statistical-Probability Evidence and the Appearance of Justice, 103 HARV. L. REV. 530, 532 (1989).

54. David Ropeik, Let's Get Real About Risk, WASH. Post, Aug. 6, 2000 , at B4.

55. See Part III.

56. Empirical evidence from the Rehabilitation Act demonstrates the pressure toward a sweeping construction of the direct threat defense despite congressional intent to the contrary. See, e.g., ROTHSTEIN ET AL., supra note 14, at 190 ("Despite the congressional intent that the 'direct threat' defense is to be constructed narrowly, the courts in pre-ADA cases have given careful attention and some degree of deference to employer concerns about safety-especially public safety."). 


\section{risk avoidance. ${ }^{57}$}

In addition, errors in the opposite direction-false negatives-harm employers, coworkers, and customers, all of whom constitute the "others" referred to in the text of the direct threat defense. ${ }^{58}$ Decision makers, when left to their own devices, may resort to biases that favor sympathetic disabled plaintiffs and disfavor unsympathetic employers. Sympathy for certain categories of disabled individuals may result in decisions that overweight the value of employing the disabled and underweight the harm to abstract employers and third parties. Mistaken findings of no direct threat result in employees who pose significant risks in the workplace because they have mistakenly been allowed to work.

Policy makers should discipline the significant risk decision in a manner that facilitates accurate decision making. Given that the ADA puts the significant risk decision in the hands of judges and juries, "[t]he government's responsibility in generating and using risk information involves structuring a decision process in which individuals and societal institutions work together." 60 If "one . . view[s] the jury as a risk manager responsible for promoting an efficient and socially acceptable level of risktaking behavior by society's citizens and corporations," then it is critical that policy makers provide juries with the tools they need to perform the function assigned to them. ${ }^{61}$ We should not require juries to make decisions

In order for the direct threat defense to exist as part of the ADA while not undermining the intent of the ADA, it must ensure that significant risk decisions are not based on "the prejudiced attitudes or the ignorance of others.” Sch. Bd. of Nassau County v. Arline, 480 U.S. 273, 284 (1987); see Bay Area Addiction Research and Treatment, Inc. v. City of Antioch, 179 F.3d 725, 736 (9th Cir. 1999). The legislative history of the ADA supports the notion that we should avoid direct threat determinations based on stereotypical fears of the disabled: "The determination that an individual with a disability will pose a direct threat to others... must not be based on generalizations, misperceptions, ignorance, irrational fears, patronizing attitudes, or pernicious mythologies." S. REP. No. 116, 101st Cong., 1st Sess. 27 (1989); H.R. REP No. 485, 101 st Cong. 2d Sess. pt. 2, at 56 (1990) (Committee on Education and Labor).

This Article contends that direct threat determinations made under a balancing test (standards) are more likely to embody such generalizations, misconceptions, and ignorance than if they were made with the assistance of numerical anchors (closer to rules). While the ADA's focus on case-specific determinations, see 29 C.F.R. $\S 1630.2(r)$, may help to alleviate the problem of generalizations and stereotypical assumptions of direct threat, statistical benchmarks could further limit discretion and cabin the effects of prejudice without significantly adding to the costs of making such decisions.

57. "Rational risk avoidance" refers to the notion that we should prioritize in order to target limited resources at the reduction of the most significant risks. Failure to rationally prioritize and avert risks results in massive harm to society. "Hundreds of thousands of Americans will die this year, deaths that can be prevented. Millions will get sick with preventable illnesses. Billions of dollars and countless hours of human effort will be wasted unnecessarily-all because we are afraid of the wrong things." Ropeik, supra note 54, at B1.

58. See supra text accompanying note 24 .

59. See supra note 23.

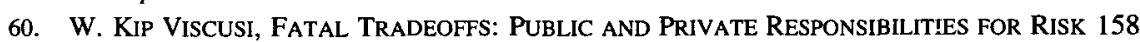
(1992).

61. Reid Hastie \& W. Kip Viscusi, What Juries Can't Do Well: The Jury's Performance as a Risk 
that they are incapable of making well.

The following discussion describes and evaluates current direct threat jurisprudence and concludes that the decisions are inconsistent and potentially inaccurate.

III.

\section{CURRENT DIRECT THREAT JURISPRUDENCE: WHEN DOES AN INDIVIDUAL POSE A "SIGNIFICANT RISK"?}

Juries determining whether a given plaintiff poses a significant risk are immediately confronted by an obvious and seemingly simple question: How large must a risk be to count as significant? ${ }^{22}$ This Part addresses whether juries and judges are consistently and accurately answering this question. Determinations under existing doctrine serve as a baseline by which to measure the potential benefit of adopting the statistical benchmarks discussed in Part V: If current decisions are often inconsistent or inaccurate then the case for statistical benchmarks, to rationalize existing practice, improves. A finding of inconsistency or error is also important in itself. The conclusion that juries and judges are doing a bad job sorting significant from insignificant risks stands independently of the numerical benchmarks proposal.

The following discussion focuses on two strands of cases-those involving $\mathrm{HIV}$-positive plaintiffs and mentally ill plaintiffs-to provide examples of inconsistent and inaccurate direct threat determinations. By highlighting some plausible scenarios for irrational risk determinations, this Part establishes a presumption against the existing doctrine's ad-hoc inquiry. ${ }^{63}$ Although the methodology is too informal ${ }^{64}$ to support strong

Manager, 40 ARIZ. L. REv. 901, 902 (1999); see also A. Mitchell Polinsky \& Steven Shavell, Punitive Damages: An Economic Analysis, 111 HARV. L. REV. 869, 878-900 (1998).

62. Numerous other questions abound: May or must courts, consistent with expected utility models, discount the potential harm by the (im)probability of its occurrence? Is there a minimum probability or harm below which a risk is per se insignificant or is a minuscule probability of a terrible end state sufficient for a successful employer defense? For example, is a one-hundred percent probability of a bump or a bruise sufficient to establish a significant risk, or, at the other extreme, is a one in one million probability of a nuclear meltdown or an airplane crash sufficient given the sheer magnitude of the harm? These questions, of course, are difficult to answer in any principled way without some benchmark for disciplining the question posed in the text: What counts as significant?

63. A presumption of misprioritization seems particularly robust in light of the fact that prioritization and rational risk reduction rarely come about on their own. Absent an attempt to prioritize, a host of external factors cut against accurately prioritized decision making.

Many biases in risk perception stem from the fundamental nature of risk. A flood of empirical results and interpretations has demonstrated that people are not well-endowed to reason coherently about the probabilities of occurrence of individual events. Studies of juries' competency in comprehending and applying probabilistic evidence have also concluded that jurors are very limited in this regard and that, by and large, information about probabilities is often misunderstood and misused.

Hastie \& Viscusi, supra note 61, at 909-10. Therefore, so long as we can at least say that the accuracy of 
generalizations, the clear and consistent problems surfacing in the cases considered are evidence for a more modest claim that current direct threat decisions are inconsistent and inaccurate.

\section{A. Cases Involving HIV-Positive Disabled Individuals}

Cases involving HIV-positive plaintiffs alleged to pose a significant risk in the workplace are a good place to begin analyzing the consistency and accuracy of current determinations. ${ }^{65}$ Decision makers, given relatively free reign to impose their judgments of significant risk, may find some disabilities to pose more of a risk than others based on subjective and unfounded fears, ${ }^{66}$ misbeliefs, and prejudices attached to certain disabilities. If this is the case, then we should expect to see HIV risk assessments that are incommensurate with statistical risk. ${ }^{67}$

"Throughout history, illness has often been regarded as one form of punishment imposed for wrongdoing. Plagues, paralysis, and blindness are just some of the retributions imposed by divine powers on sinning others, as illustrated in the Oedipal myth." 68 Although modern society has generally moved away from blaming the victim of disability, the perception of certain disabilities as being deserved by the victim persists. ${ }^{69} \mathrm{HIV}$ is a paradigm example. In many circumstances, HIV-positive individuals are likely to elicit "social reprimand" resulting from judgments that the individual is to blame for a condition over which he had causal control. ${ }^{70}$ Furthermore,

status quo decisions is unclear, it makes sense to presume the decisions are inaccurate.

64. Cases examined were the fifty-seven Supreme Court and circuit court of appeals cases out of the 189 Supreme Court, appellate court, and district court cases retrieved by a Lexis search, on March 28,2000 , in the "mega; mega" library, for the terms "ADA and direct threat." Some additional district court cases were also considered.

65. Between June 26, 1992 and June 30, 1995, 1.8 percent of cases received by the EEOC were filed by plaintiffs alleging HIV as a disability ( 903 cases in total). Kathryn Moss, The ADA Employment Discrimination Charge Process: How Does It Work and Whom Is It Benefiting?, in EMPLOYMENT, DISABILITY, AND THE AMERICANS WITH DISABIIITIES ACT, supra note 14, at 118, 124.

66. "By definition, fear is more emotional than rational. We fear before we think." Ropeik, supra note 54, at B4. Absent an attempt to constrain how certain fears influence direct threat decision making, we are likely to be left with less than rational results.

67. Common sense judgments by judges or jurors are quite likely to be inaccurate in the context of contagious diseases, where fear and misperception are at their height. See Sch. Bd. of Nassau County v. Arline, 480 U.S. 273, 284 (1987) ("[F]ew aspects of a handicap give rise to the same level of public fear and misapprehension as contagiousness."). "[I]ndividuals with [contagious diseases] are in particular need of statutory protection; otherwise "they would be vulnerable to discrimination on the basis of mythology-precisely the type of injury Congress sought to prevent."' Holiday v. City of Chattanooga, Docket Number 98-5619, 2000 U.S. App. LEXIS 3660, *27 (6th Cir. Mar. 10, 2000), quoting Arline, 480 U.S. at 285.

68. BERNARD WEINER, JUDGMENTS OF RESPONSIBILITY: A FOUNDATION FOR A THEORY OF SOCIAL CONDUCT 57 (1995).

69. Id.

70. Id. at 245 . 
blatant prejudice toward HIV-positive individuals persists despite efforts by the medical community to allay unfounded fears." "Perhaps the most stigmatizing condition in contemporary society is AIDS." "72

An examination of recent cases demonstrates that current direct threat decisions appear to treat HIV-positive individuals differently than other disabled individuals for reasons other than a difference in the statistical risk they pose to others. Rather than reflecting statistical differences in risk, distinctions between HIV-positive individuals and other disabled individuals are more likely a reflection of the prejudice and inconsistent treatment that the ADA seeks to eradicate. Onishea $v$. Hopper ${ }^{73}$ and Montalvo v. Radcliffe ${ }^{74}$ are two paradigm examples of this phenomenon. These cases illustrate both the inconsistency and inaccuracy of current direct threat jurisprudence.

In Onishea v. Hopper, the plaintiffs brought suit under section 504 of the Rehabilitation Act of $1973,{ }^{75}$ alleging that an Alabama Department of Corrections policy segregating HIV-positive prisoners from the general prison population was unlawful. ${ }^{76}$ The court upheld the policy denying HIV-positive prisoners access to many educational, religious, and recreational programs. ${ }^{77}$ The Onishea court rejected the plaintiffs' expert testimony, which empirically demonstrated that "incidents of HIV transmission in many activities are rare or virtually unknown," ${ }^{78}$ in favor of the defendant's testimony asserting that "HIV transmission is theoretically possible, even if not documented." 79 Although the court correctly asserted

71. Discrimination against HIV-positive individuals is pervasive. WEINER, supra note 68 , at 103 ("The quotation... that 'homosexuals have declared war on nature and now nature is extracting an awful revenge' reflects a sentiment expressed by many in the general public. . . 26\% of a sample of nurses and $11 \%$ of a sample of physicians either fully agreed with or considered the following statement as possibly true: 'AIDS is God's punishment to homosexuals."); David M. Studdert \& Troyen A. Brennan, HIV Infection and the Americans with Disabilities Act: An Evolving Interaction, 549 ANNALS AM. ACAD. POL. \& SOC. SCI. 84, 85 (1997) (noting that HIV-positive individuals "experience discrimination in many facets of societal life" and remain objects of fear and stigmatization).

72. WEINER, supra note 68 , at 115.

73. 171 F.3d 1289 (11th Cir. 1999).

74. 167 F.3d 873 (4th Cir. 1999).

75. 29 U.S.C. $\$ 794$ (1994). Although Onishea interpreted the Rehabilitation Act, the case is directly relevant to the ADA's direct threat inquiry. The ADA's direct threat defense, including the significant risk language, is based on the Rehabilitation Act and Congress intended courts to interpret the ADA's direct threat provision in light of Rehabilitation Act precedent. See supra notes 25-27 and accompanying text (documenting the relationship between the direct threat defense of the ADA and the Rehabilitation Act). While not a perfect' match, "the Rehabilitation Act case law provides useful guidance on how courts approach safety issues and how they will assess the validity of an employer's safety requirements." BURGDORF, supra note 5, at 253

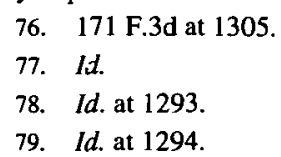


that the significance of a risk is a function of the probability of the harm occurring and the magnitude of the harm, ${ }^{80}$ it proceeded to collapse the inquiry, noting that "the risk of transmission can be significant even if the probability of transmission is low: death itself makes the risk "significant." "81

The Onishea court ratified a decision making process that conflates the probability and outcome variables by declaring that any risk of even one death is too large of a risk to tolerate ${ }^{82}$ The court was correct in its claim that we should tolerate lower probabilities as the magnitude of the potential harm increases. However, by focusing only on the "severity" prong of the Arline four-part test, which also includes likelihood of the harm, duration of the risk, and imminence, ${ }^{83}$ the court justified a finding of significant risk by focusing on the potential harm but remaining insensitive to probability. ${ }^{84}$ It is one thing to say that a lower probability threshold will suffice when the potential harm is more severe, but it is quite another thing to hold that any risk of probability, no matter how small, is enough to make the risk significant.

Another discussion of significant risk allegedly posed by an HIVpositive plaintiff is a Fourth Circuit case interpreting Title III of the ADA. In Montalvo v. Radcliffe, a 12-year old HIV-positive plaintiff was denied admission to a karate class. ${ }^{85}$ The court affirmed the legality of denying admission on the ground that the plaintiff posed a significant risk to other class members. ${ }^{86}$

Although the court purported to apply the four significant risk factors mandated by the EEOC and originally announced in Arline (nature, duration, severity, and probability of the risk), ${ }^{87}$ it instead performed a haphazard risk analysis giving little weight to probability and focusing almost exclusively on the fact that the plaintiff had AIDS-a deadly disease ${ }^{88}$ The court carefully considered the severity of the potential harm, discussing the nature of the risk and listing the possible methods of transmitting AIDS in a karate class. It also discussed the duration of the

80. Id. at 1297 ("[T]he significance of a risk is a product of the odds that transmission will occur and the severity of the consequences.").

81. Id.

82. Id. at 1299.

83. See supra notes $38-39$ and accompanying text.

84. See Onishea, 171 F.3d at 1306 (Barkett dissenting) ("Focusing exclusively on Arline's third factor, the majority holds that, because of its deadly consequences, any cognizable risk of HIV transmission is, as a matter of law, a significant risk. . . . Although it disclaims any intent of establishing an 'any risk' standard, in fact the majority opinion does exactly that.").

85. 167 F.3d 873,874 (4th Cir. 1999).

86. Id. at 878 .

87. See supra notes $38-39$ and accompanying text.

88. 167 F.3d at 878 . 
risk, which it defined as the entire length of the plaintiff's life ${ }^{89}$ The court paid close attention to the severity of the risk, noting that the potential harm is "extreme because there is no known cure for AIDS" and because AIDS is "inevitably fatal." 90

Finally, the court discussed the probability that the harm of transmission would be realized. ${ }^{91}$ Similar to the analysis in Onishea, the Montalvo court collapsed the probability inquiry into its consideration of the potential harm. Recall that probability is a crucial variable to the significant risk determination because even a very large harm poses an insignificant risk when the probability of its occurrence is sufficiently low. ${ }^{92}$ The court was insensitive to probability, however, noting that "the exact mathematical probability of transmission is unknown" and then simply asserting that "the mode of transmission is one which is likely to occur." The court concluded that "the nature of the risk, combined with its severity, creates a significant risk" without even mentioning probability. ${ }^{94}$ Essentially, the court concluded that the risk is significant because, if it were to come to pass, it would be terrible. ${ }^{95}$ The court recognized this much and attempted to justify its analysis by asserting that "[w]hen balancing the Arline factors to determine whether a risk is significant, one need not conclude that each factor is significant on its own. Rather, the gravity of one factor might well compensate for the relative slightness of another." 96 The court's statement is surprising in light of the language of regulations implementing the ADA's direct threat provision: discrimination is not permitted "merely because of a slightly increased risk. The risk can only be considered when it poses a significant risk, i.e., high probability of substantial harm; a speculative or remote risk is insufficient." ${ }^{\prime 97}$ Although the court was correct to hold that each Arline factor need not be significant

89. This, of course, is odd given that it is difficult to see how it could be relevant that the plaintiff will have AIDS for the duration of his life when the court is only assessing the probability of transmission during a children's karate class. See id. It seems that the relevant variable should be the amount of time others are exposed to the risk posed by the plaintiff-the once-a-week karate class rather than the duration of the plaintiff's life.

90. Id.

91. Id.

92. See NICHOLAS RESCHER, EMPIRICAL INQUIRY (1982). This explains, in part, why most people do not lie awake at night worrying about being hit by as asteroid or being struck by lighting-the risk is so low as to be considered irrelevant.

93. Montalvo, 167 F.3d at 878 .

94. Id.

95. For a similar line of analysis, see Bradley v. University of Texas M.D. Anderson Cancer Ctr., 3 F.3d 922, 924 (5th Cir. 1993) (per curiam) (concluding, under the Rehabilitation Act, that any cognizable risk is sufficient to render an HIV-positive plaintiff a direct threat because of HIV's letha] consequences).

96. Montalvo, 167 F.3d at 878.

97. 29 C.F.R. $\S 1630.2(r)$ app. (emphasis added). 
on its own, the court appears on more shaky ground when it finds a significant risk based only on the severity of the harm and insensitive to the probability of its occurrence. ${ }^{98}$

The preceding cases' emphasis on the severity of HIV transmission and insensitivity to probability of transmission lay the groundwork for two separate arguments. First, the finding of significant risk in HIV/AIDS cases and not in cases involving other disabilities posing similar risks provides a foundation for the inconsistency claim: juries and judges, in the absence of more rigid guidance, will disparately treat disabled individuals posing equivalent risks. Second, juries' and judges' willingness to find significant risk in HIV/AIDS cases, even in instances of a miniscule probability of transmission, evidences the inaccuracy claim: these decisions are infected by subjective fears, misbeliefs, and prejudices, directed toward HIVpositive individuals, which result in mistaken findings that such individuals pose a direct threat. The following discussion examines the inconsistency and inaccuracy claims in light of the preceding cases.

\section{Inconsistent Evaluations of HIV}

The unanchored decision making evident in cases such as Onishea and Montalvo provides evidence for the inconsistency claim. Individuals posing equivalent risks in the workplace are being treated differently based on the source of the risk they pose to others. That is, decision makers are quite insensitive to probability when evaluating the risk posed by HIV-positive plaintiffs. But, as hypothesized below, decision makers are more attuned to probability in cases of other disabilities. Although juries and judges should be willing to accept lower probabilities of more severe harms, similar probabilities should be demanded in cases of equivalent potential harms. Unfortunately, it appears that when a harm is feared or stigmatized, such as AIDS, any risk of the harm occurring may be enough for a decision maker to categorize the risk as significant. Juries and judges determining whether a risk of transmitting HIV is significant seem transfixed by the severity of the harm and extremely insensitive to the probability of transmission. Other harms, however, which may objectively be as large, are found insignificant on the grounds that they are improbable. ${ }^{99}$ In the current system, disparate

98. See Adam G. Forrest, Note, Is There a Significant Risk or High Probability of HIV Transmission from an Infected Health Care Worker to Others? The Sixth Circuit's Answer Lies in Mauro v. Borgess Medical Center, 32 CREIGHTON L. REv. 1763, 1803 (1999) (stating that "[i]n light of the Sixth Circuit's Conclusions [in Mauro v. Borgess Medical Center, 137 F.3d 398 (6th Cir. 1998)], the next court to deal with this issue will, more than likely, err by ruling that some possibility of harm is enough ... to pose a significant risk .... [S] uch a holding would be wholly inconsistent with the high probability ... that is required by the ... ADA.").

99. See, e.g., Rizzo v. Children's World Learning Ctrs., Inc., 173 F.3d 254, 260 (5th Cir. 1999) 
treatment of the probability variable across categories of disabilities gives rise to inconsistency-decision makers are sensitive to probability for some categories of harms but not for others.

If the HIV/AIDS examples are any indicator, individuals with uniquely stigmatized disabilities appear more likely to be found to pose a significant risk. Whether this is because juries and judges are extremely fearful of HIV transmission or because they believe that HIV-positive plaintiffs are to blame for their condition, ${ }^{100}$ decision makers appear intolerant of miniscule probabilities of harm potentially resulting from the presence of HIVpositive individuals. Blatant prejudice toward HIV-positive individuals may result in juries' willingness to exclude these individuals from the workplace regardless of the statistical risk they pose. ${ }^{101}$

\section{Inaccurate Assessments of HIV}

Decision making of the sort illustrated in Onishea and Montalvo buttresses the claim that direct threat determinations are inaccurate in the current system. By ignoring the probability variable or setting the probability threshold near zero, decision makers will find any risk significant so long as it is a risk of a particular type of feared, stigmatized harm. It is not difficult to imagine a scenario whereby most any disabled individual, if allowed to work, could be found to pose a significant risk under the Montalvo analysis. All the employer would have to demonstrate is that there is some imaginable, non-zero risk of a massive harm, for example death, posed by the plaintiff. The employer could then assert that, whatever the probability, since the harm is large, when all the balancing is said and done the risk is significant. The result of such decision making is that tiny harms, were they properly discounted based on their (im)probability, are mistakenly found to be significant.

Such an analysis, unconstrained by a need to demonstrate a certain probability of a given harm occurring, is likely to create room for the stereotypical fears that the ADA seeks to eliminate. Instead of rationally prioritizing risks, direct threat decision making is a paradigm example of how "we make policy based more on fear than fact." 102 People can and often do overestimate the overall risk posed by individuals with uniquely feared or stigmatized disabilities. The Montalvo analysis licenses alarmist decision making by allowing parties to give little weight to statistical risk and simply

(holding that a hearing impaired bus driver did not pose a direct threat because the probability of the harm was insubstantial).

100. See supra note 70 and accompanying text.

101. See supra notes 68-71 and accompanying text.

102. Ropeik, supra note 54, at B4. 
provide evidence relating to potential harm independent of probability. Therefore, even if the current unanchored decision making process does not result in inaccuracy across the board, it is particularly likely to yield overestimates of the threats posed by those individuals most in need of the ADA's protection.

\section{B. Cases Involving Mentally Ill Disabled Individuals}

ADA cases involving mentally ill disabled individuals ${ }^{103}$ provide a second set of cases for analyzing the consistency and accuracy of current direct threat inquiries. Similar to HIV-positive individuals, those suffering from mental illness are often the victims of prejudice and misconception. "Reviewers of the literature clearly reveal that depressed persons elicit rejection from others. Rejection is manifested in both distance from and active dislike of the depressed. ... In general, depressed individuals create a negative effect on others." ${ }^{104}$ Negative social attitudes are not confined to the depressed. In a survey of public attitudes towards individuals with schizophrenia almost half of the sample "agreed that the person was morally weak and should be held personally responsible for his behavior." 105 "As a result of fears, myths, and stereotypes, people with mental disabilities continue to find themselves discriminated against in all facets of life." ${ }^{106}$

A review of recent cases supports the proposition that juries and judges evaluating risks posed by mentally ill disabled individuals are eager to find that these individuals pose a direct threat. The appearance that courts are unduly harsh or conservative when evaluating risks posed by the mentally ill should give observers reason to pause. We might think that harsh treatment, falling disproportionately on groups of disabled individuals most feared by society, is a symptom of, or at least facilitated by, an unguided and unprincipled inquiry. The argument does not require a finding that

103. "[I]t is ironic that the highest incidence of disability is psychiatric, and yet psychiatric disability promotes the greatest prejudice." Miller, supra note 14, at 12 n.7. Between June 26, 1992 and June 30, 1995, 11.8 percent of cases received by the EEOC were filed by plaintiffs alleging psychiatric disabilities (5,872 cases in total). Moss, supra note 65, at 124. Between 1992 and 1998, 15 percent of ADA claims filed with the EEOC were based on emotional or psychiatric impairments. See EEOC, Americans with Disabilities Act of 1990 (ADA) Charges FY 1992-1998, available at http://www.eeoc.gov/stats/ada.html (visited Mar. 1, 2001); Danforth, supra note 23, at 673. For instance, in 1998, individuals claiming psychiatric or emotional impairments were one of the largest single categories of plaintiffs. See Americans with Disabilities Act of 1990 (ADA) Charges FY 1992-1998, supra. Claims by individuals with mental illness are one of the few categories of ADA claims filed with the EEOC that have increased in percentage terms since the ADA's enactment in 1990. See id.

104. WEINER, supra note 68, at 119 (citations omitted); see id. at 128 ("Depression is considered a sin; as such, it results in social reprimand.").

105. Id. at 129.

106. Miller, supra note 14 , at 12 n.7. 
decision makers are intentionally discriminating against the mentally ill. It is likely that, left with a discretionary balancing test, judges and juries are unable to rely on any bright-line rules and instead revert to heuristics that often include misconceptions in order to implement an otherwise unworkable multi-factor inquiry. Several cases illustrate these problems.

In Doe v. Region 13 Mental Health-Mental Retardation Commission, ${ }^{107}$ the Fifth Circuit held that a "superior employee" who "did an excellent job" 108 working as an associate in a community mental health center was terminated legally after being diagnosed with "depressive neurosis." 109 She posed a direct threat to others. At first glance, the rationale that "a therapist who accepts suicide ... may pass along this bias to his or her patients" 110 seems unremarkable. ${ }^{11}$ The opinion is surprising, however, when one considers that there was no discussion of the probability of the asserted harm occurring. Although the center presented evidence that the potential harm might result, ${ }^{112}$ this evidence established a mere possibility rather than a probability of harm. There was no evidence that the plaintiff had ever passed on her alleged "bias" toward committing suicide to a single patient-with respect to the plaintiff the risk was only theoretical. In fact, the plaintiff, in a prior civil commitment proceeding, was found to not be suicidal. ${ }^{113}$

Disturbingly, the court was explicit in allowing a relaxed probability requirement because the plaintiff's disability was mental, not physical. The court noted, "This is not a case involving whether an employee is able to screw nuts and bolts. ... No such cut-and-dried factual proof is available when dealing with the 'soft science' surrounding... affliction of an individual's psyche." 114 In the absence of any "hard" proof, the court was content to rely on evidence demonstrating a possibility that the plaintiff posed a direct threat, rather than require evidence establishing a high probability as required by the ADA. ${ }^{115}$

There are a host of additional cases holding that mentally ill plaintiffs were legitimately discharged because they posed a direct threat in the

107. 704 F.2d 1402 (5th Cir. 1983). Doe interprets the Rehabilitation Act's "direct threat" provision. Rehabilitation, Comprehensive Services, and Developmental Disabilities Act of 1978, Pub. L. No. 95-602, § 122(a), 92 Stat. 2955, 2984-85 (1978). See supra notes 25-27 and accompanying text.

108. 704 F.2d at 1404 .

109. Id.

110. Id. at 1409 .

111. The following discussion of Doe draws from a discussion of the case in BURGDORF, supra note 5 , at $255-58$.

112. 704 F.2d at 1409.

113. Id. at 1406.

114. Id. at 1410 .

115. See supra text accompanying note 30 (quoting the 29 C.F.R. $\S 1630.2(r)$ app. language requiring a "high probability"). 
workplace. ${ }^{116} \mathrm{~A}$ rough sketch of the type of plaintiff that courts are willing to find poses a direct threat provides a meaningful baseline for assessing whether courts consistently treat mentally ill plaintiffs the same as nonmentally ill plaintiffs posing equivalent objective risks. Holding constant the severity of harm posed by plaintiffs, decision makers err by inconsistently discounting the relevance of probability. That is, judges and juries behave inconsistently by exhibiting insensitivity to probability for harms caused by the mentally ill but remaining attuned to probability for harms threatened by otherwise disabled individuals.

Consider the following three cases. In Layser v. Morrison, ${ }^{117}$ the court held that an individual suffering from depression posed a direct threat. The plaintiff, an armed campus security officer suffering from stress and depression, reported that he had dreamt of shooting his supervisor. ${ }^{118}$ The plaintiff, Layser, was so disturbed by his own dream that he reported it to a psychologist. ${ }^{119}$ The psychologist, in turn, reported Layser's dream to Layser's supervisor, who responded by stripping Layser of his firearm and forcing him to go on leave until he could be deemed psychologically fit to work. ${ }^{120}$ Upon agreement between Layser's psychologist and Layser's supervisor, Layser was permitted to return to work as an unarmed dispatcher and, about one year later, returned to partial duty. ${ }^{121}$ Layser brought suit under the ADA alleging that his temporary reassignment to a dispatcher position constituted unlawful discrimination. Without undertaking an in-depth inquiry, and without mentioning the Arline probability factor, the court ruled in favor of the defendant-college on the ground that Layser's dream along with statements from his psychologist and Layser's own contemporaneous statements were "sufficient submissions to illustrate the potential harm [that] Layser posed was significant." 122

Similarly, the court in Keith v. Ashland, Inc. ${ }^{123}$ held that an individual suffering from clinical depression posed a direct threat. The plaintiff in Keith, a driver and handler of toxic chemicals for an oil company, was permissibly discharged because he "had been disciplined on several occasions and did not seem capable of properly performing his duties" and

116. See, e.g., Keith v. Ashland, Inc., 98-4539, 2000 U.S. App. LEXIS 1940 (6th Cir. Feb. 8 , 2000); Shipplet v. Nat'l R.R. Passenger Corp., 97-2056, 1999 U.S. App. LEXIS 14004 (6th Cir. Jun. 17, 1999); Layser v. Morrison, 935 F. Supp. 562 (E.D. Pa. 1995).

117. 935 F. Supp. 562 (E.D. Pa. 1995).

118. Id. at 565 .

119. Id.

120. Id.

121. Id.

122. Id. at 569 .

123. 98-4539, 2000 U.S. App. LEXIS 1940, *13-14 (6th Cir. Feb. 8, 2000). 
therefore posed a direct threat. ${ }^{124}$

Finally, in Shiplett v. National Railroad Passenger Corp., ${ }^{125}$ a railroad engineer taking the prescription drug Xanax to alleviate sleep disorders, anxiety, and panic attacks, posed a direct threat to others. ${ }^{126}$ The court, given its self-professed lack of expertise on the issue, deferred to the findings of Amtrak and federal agencies (the National Transportation Safety Board and Federal Railway Administration) that the use of Xanax posed "too significant of a risk to the safety of the operation of a train to justify its use." 127 This conclusion was based on the evidence in the record demonstrating that the potential side effects of Xanax may include "drowsiness, memory impairment, light-headedness, and impaired coordination." 128

The issue raised by cases such as these is whether juries and judges are making consistent direct threat determinations or, instead, relying on misconceived stereotypes about the mentally ill to find a direct threat when, in reality, there is none. The inconsistency concern arises from these cases' failure to evaluate probability carefully. Although the courts engage in textured descriptions of the potential harms posed by the plaintiffs, their cursory evaluation of probability gives rise to a strong inference that the decisions fail to take sufficient account of this critical variable. The inaccuracy concern stems in part from courts' failure adequately to consider probability and also from juries' and judges' misinformation that leads to this insensitivity to such an important variable. The following discussion links the preceding cases to the inconsistency and inaccuracy themes.

\section{Inconsistent Evaluations of the Mentally Ill}

The free-floating or nonexisting analysis of probability found in many ADA cases involving mentally ill plaintiffs supports the claim that individuals posing equivalent risks are treated differently depending on the source of the risk they pose to others. When the source of the risk is mental illness, juries and judges exhibit a readiness to cast aside considerations of probability. But in other cases, where the plaintiff suffers from a less stigmatized, more pallid disability such as hearing impairment or back pain, decision makers are likely to be more attuned to probability.

The result of juries' and judges' insensitivity to probability in cases involving mentally ill plaintiffs is that some of the plaintiffs found to pose a

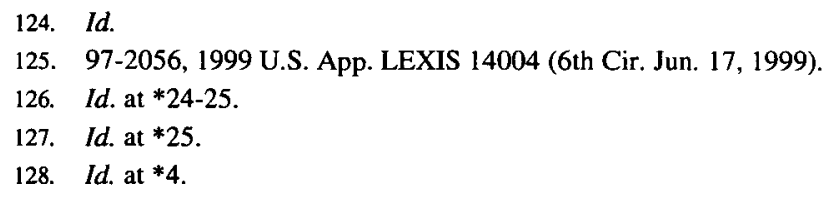


direct threat probably do not. By focusing on the potential harm done by these plaintiffs, but failing to discount this harm by its improbability, decision makers overestimate the overall risk posed by the mentally ill. Were these plaintiffs to pose an equivalent risk from a less stigmatized or less visceral disability, and were decision makers adequately to consider probability, the same plaintiffs would probably not be deemed to pose a significant risk to others.

The $D o e^{129}$ case is one example of inconsistent categorization of the mentally ill. The plaintiff was categorized as a direct threat partly because she was mentally ill, but not based on any explicit assessment of probability. The court, failing to consider probability, held that the plaintiff posed a direct threat based on evidence demonstrating a merely theoretical risk of harm. Furthermore, the court explicitly relied on a reduced probability requirement because the plaintiff's disability was mental, not physical. The Doe court, by overtly linking its insensitivity to probability to the nature of the plaintiffs disability, provides strong evidence for the hypothesis that decision makers may be more likely to cast aside the law's probability requirement for certain types of disabilities.

The plaintiff in Layser ${ }^{130}$ is another example. In Layser, the court drew an immediate inference that a depressed, armed security officer who dreamt of shooting another individual presented a high probability of actually shooting another individual. Considering that people often dream of taking actions that they never carry out when awake, the court appears to have seized on the worst-case scenario. In one sense, Layser is a paradigm example of a decision maker failing to consider probability because of the source of the potential harm. The court appears willing to assume that the plaintiff poses a significant risk simply because the potential harm is large. An important gap in the court's reasoning is that the risk is significant only if there is some likelihood of it in fact occurring. The fact that the plaintiff was depressed appears to have supercharged the court's willingness to extrapolate a high probability from only a dream. The plaintiff's depression somehow gave his dreams more significance.

Comparing the several cases in which mentally ill plaintiffs were found to pose a direct threat to cases involving individuals with disabilities other than mental illness, where no direct threat was found, provides further evidence of inconsistent direct threat determinations across categories of disabilities. In both Keith ${ }^{131}$ and Shiplett ${ }^{132}$ the court found that a mentally ill plaintiff posed a direct threat. Recall that in Keith, the court held that a

\footnotetext{
129. Doe v. Region 13 Mental Health-Mental Retardation Comm'n, 704 F.2d 1402 (5th Cir. 1983 ).

130. Layser v. Morrison, 935 F. Supp. 562 (E.D. Pa. 1995).

131. Keith v. Ashland, Inc., 98-4539, 2000 U.S. App. LEXIS 1940 (6th Cir. Feb. 8, 2000).

132. Shiplett v. Nat'l R.R. Passenger Corp., 97-2056, 1999 U.S. App. LEXIS 14004 (6th Cir. Jun.
} 17, 1999). 
handler of toxic chemicals suffering from depression posed a direct threat, ${ }^{133}$ and in Shiplett, the court found that a railroad engineer taking the prescription drug Xanax to alleviate panic attacks posed a direct threat. ${ }^{134}$

A comparison of these cases involving the mentally ill to cases involving other categories of disabilities is illustrative. For instance, in Kinney Shoe, ${ }^{135}$ a shoe salesmen suffering from epileptic seizures was found not to pose a direct threat because, according to the court, a seizure posed neither a significant risk nor a substantial harm. ${ }^{136}$ Similarly, in Rizzo $v$. Children's World Learning Centers, Inc., ${ }^{137}$ the court found that a hearingimpaired bus driver did not pose a direct threat because the probability of the harm was insubstantial. ${ }^{138}$

There is not a sensible line that divides these cases. In both the cases involving the mentally ill and the cases involving otherwise disabled individuals the evidence cut both ways on the direct threat issue. In both sets of cases, there were large harms at stake-both the mentally ill and the non-mentally ill plaintiffs posed a risk of death to others were the worstcase scenario to materialize. However, in both Kinney Shoe and Rizzocases involving non-mentally ill plaintiffs-the court put the party alleging a direct threat up to the difficult task of substantiating a hypothetically risky scenario with hard data. Furthermore, when dealing with the non-mentally ill, the court specifically required a showing of high probability-the element that was lacking in the cases against the mentally ill. For instance, in Rizzo, the court held that, although a small child choking to death is a large harm, there was only a theoretical, unsubstantiated possibility that the harm would come to pass. ${ }^{139}$ For a partially deaf plaintiff, the absence of a high probability was enough to rule out a finding that the plaintiff posed a direct threat. ${ }^{140}$

On the other hand, in the cases involving the mentally ill, the court is more willing to defer to authorities alleging a direct threat and to presume that possible scenarios were, in fact, probable outcomes. ${ }^{141}$ This finding is consistent with the hypothesis that courts employing direct threat analysis view certain categories of disabled individuals through a different lens.

133. 2000 U.S. App. LEXIS 1940, at *13-14.

134. 1999 U.S. App. LEXIS 14004, at *24-25.

135. EEOC v. Kinney Shoe Corp., 917 F. Supp. 419 (W.D. Va. 1996), aff'd sub nom. Martinson v. Kinney Shoe Corp., 104 F.3d 683 (4th Cir. 1997).

136. 917 F. Supp. at 429.

137. 173 F.3d 254 (5th Cir. 1999).

138. Id. at 260 (noting that there was no empirical evidence in the record of any problems associated with the plaintiff driving a van).

139. Id.

140. Id.

141. See Doe v. Region 13 Mental Heaith-Mental Retardation Comm'n, 704 F.2d 1403, 1409 (5th Cir. 1983); Layser v. Morrison, 935 F. Supp. 562, 569 (E.D. Pa. 1995). 
When dealing with mentally ill plaintiffs, the court justifies relaxing the probability requirement either by holding that parties should not be expected to provide hard data when dealing with the "soft science" of mental illness ${ }^{142}$ or by finding that a high probability has been demonstrated on the basis of scanty evidence. ${ }^{143}$ In either instance, the ADA's goal of combating discrimination is reduced to only helping certain categories of disabled individuals. ${ }^{144}$ The disabled individuals most feared, misunderstood, or stigmatized by society remain less protected as a result of an unanchored direct threat analysis.

\section{Inaccurate Assessments of the Mentally Ill}

Cases such as Doe also provide a strong basis for the claim that current direct threat determinations are inaccurate. First, the Doe court sanctioned firing a disabled individual based on a highly speculative risk. The likelihood of Doe passing on a willingness to commit suicide to her patients was unevidenced. The scenario was based on a possibility, not a probability, in direct contradiction to the EEOC's admonition that a "slightly increased risk" is an insufficient basis for denying employment and that decision makers may not even consider the risk unless it is a "high probability" as opposed to a "speculative or remote risk." 145

Second, the court explicitly stated that it was allowing more diffuse evidence to establish proof of significance in the context of mental illness. Instead of adhering closely to the text of the ADA, the Doe court departed from the presumed need for "cut-and-dried factual proof." 146 The court justified this less exacting inquiry based on the nature of the plaintiff's disability and, in doing so, demonstrated a clear willingness to subject claims that the mentally ill are a direct threat to a lower standard of proof. In essence, the court announced that parties alleging that a plaintiff is a direct threat as a result of mental illness need not make the typical showing under the Act-because mental illness is surrounded by what the court referred to as "soft science," 147 defendants are given greater latitude merely

\footnotetext{
142. Doe, 704 F.2d at 1410 .

143. See Layser, 935 F. Supp. at 569.

144. See H.R. Rep. No. 101-485, pt. 3, at 45-46 (1990) (discussing application of the direct threat defense to plaintiffs with mental illness and stating that a decision may not "be based on speculation about the risk of harm to others. Decisions are not permitted to be based on generalizations about the disability" and that "in the case of a person with mental illness there must be objective evidence from the person's behavior that the person has a recent history of committing overt acts or making threats which caused harm or which directly threatened harm.").

145. 29 C.F.R. $\$ 1630.2(r)$ app.

146. 704 F.2d at 1409.

147. Id. at 1406 .
} 
to assert that plaintiffs pose a direct threat, even if such assertions are grounded more in stereotypes than in reality. The ADA's goal of combating discrimination is thwarted in a particularly perverse sense because those plaintiffs most subject to misbeliefs and stereotypes are presented with an uphill battle to prove their case under the ADA. This inquiry, even more open ended than the typical direct threat determination, is ripe for the type of bias that the ADA seeks to combat. The prejudice and misconception surrounding the mentally ill $^{148}$ is more likely to affect the significant risk inquiry in the absence of benchmarks to cabin and control such tendencies. Juries and judges will predictably resort to their own prejudices in the absence of meaningful standards to guide and inform their inquiry. To the extent that these prejudices are based on misinformation, direct threat determinations will be erroneous.

The preceding discussion has addressed the positive evidence that the current direct threat decision making approach results in inconsistent and inaccurate outcomes. Although individual case studies will not support aggressive generalizations, the evidence presented here provides strong support for the limited claim that in some instances juries and judges treat similarly situated plaintiffs differently based partly on the nature of their disabilities. The following discussion presents a theory to explain further why the current unanchored approach to probability is partly to blame for these poor judgments.

IV.

EXPLANATIONS FOR INCONSISTENT AND

\section{INACCURATE DIRECT THREAT DETERMINATIONS}

A survey of the case law provides evidence of inconsistent and inaccurate direct threat determinations under existing doctrine. But what causes inconsistency and inaccuracy when decision makers attempt to distinguish significant from insignificant risks? One explanation has already been suggested: in the absence of more rigid guidelines, decision makers revert to rules of thumb. When these rules of thumb are infected with errors, the resulting direct threat decisions are likewise erroneous.

The following behavioral/cognitive theories elaborate on this explanation by demonstrating why decision makers left with insufficient guidance come to inconsistent and inaccurate judgments. This Part offers explanations for inconsistency and error that are more closely tied to the unanchored characteristic of current decision making. Behavioral explanations flesh out the rationale for why we see, and should expect to see, inaccurate and inconsistent determinations when the decision making

148. See supra notes 104-05 and accompanying text. 
process is unanchored. The explanations center on mistakes individuals commonly make when assessing risks. ${ }^{149}$ "It is . . well established that people suffer from various biases and aversions that can lead to inaccurate perceptions." 150 Decision makers with finite cognitive capacities will inevitably rely on heuristic devices. The use of these heuristics is "[a] major source of differences between actual judgments and unbiased forecasts." In other words, these heuristics sometimes result in mistakes. ${ }^{152}$

There is little reason to believe that mistakes made by the general population will not also be made by judges, juries, plaintiffs, and defendants involved in litigation under the ADA. Substantial evidence, generated by the study of cognitive errors and biases in the regulatory policymaking process, bolsters the claim that errors are not only committed by individuals making off-the-cuff calculations. ${ }^{153}$ We should expect decision makers, in the context of the direct threat determination, to commit the same kinds of errors as the general public when attempting to balance the benefits of employment of disabled individuals against the costs of such employment. ${ }^{154}$ In fact, given the large role assigned to the jury in making direct threat determinations under the current system, we should be

149. For an in-depth discussion of heuristics, biases, valuation, and their intersection with the law, see Behavioral LAW AND ECONOMICS (Cass R. Sunstein ed., 2000).

150. Cass R. Sunstein, Introduction, in BEHAVIORAL LAW AND ECONOMICS, supra note 149, at 3.

151. Christine Jolls et al., A Behavioral Approach to Law and Economics, in BEHAVIORAL LAW AND ECONOMICS, supra note 149 , at 15.

152. This is not to say that heuristic devices are not sometimes, or often, useful. The point is that they lead to predictable mistakes and that ADA significant risk determinations are an instance where heuristics are likely to contribute to erroneous risk calculations. The likelihood of mistaken risk calculations in the context of the ADA is particularly high because the determination requires decision makers to weigh costs and benefits under uncertainty and come to some conclusion about the significance of a risk. For a general discussion of the numerous ways in which decision makers are likely to employ heuristics and get the wrong answers, especially dealing with decisions related to risk, see Roger G. Noll \& James E. Krier, Some Implications of Cognitive Psychology for Risk Regulation, in BEHAVIORAL LAW AND ECONOMICS, supra note 149 , at 330.

153. "The courts are subject to a variety of potential irrationalities involving risk." Hastie \& Viscusi, supra note 61 , at 904 . Experts are no less subject to many biases than ordinary people. Experts' probability determinations are subject to the same cognitive errors as lay people, even if experts' knowledge seems to reduce the effects of biases and heuristics. See JoNATHAN BARON, THINKING AND DECIDING (2d ed. 1994); Meadow \& Sunstein, supra note 46; see also Roger G. Noll \& James E. Krier, Some Implications of Cognitive Psychology for Risk Regulation, 19 J. LEGAL STUD. 747 (1990) (explaining how risk perceptions may influence policy making); Matthew L. Spitzer, Some Implications of Cognitive Psychology for Risk Regulation: Article, 19 J. LEGAL STUD. 801 (1990) (same).

154. It might be that, given the scientific and technical expertise needed to make effective risk reduction decisions, juries are simply the wrong institution to be making these decisions in the first place. See Hastie \& Viscusi, supra note 61, at 902 ("Can the jury perform in a manner so that it serves as an effective societal risk manager?... [W]e believe that this is an extremely difficult function that is often not performed effectively even by the best informed experts. The jury is ill-informed and poorly equipped to perform this function. In our view, effective risk identification and management often requires the application of technical, statistical, and scientific analytic tools that cannot be effectively communicated to the unschooled layperson through expert testimony in adversarial procedures."). 
particularly worried that the kinds of errors made by the general public will find their way into the direct threat determination.

\section{A. The Modulus Problem}

The "modulus"155 problem refers to the phenomenon that decision makers, potentially agreeing on fundamental value judgments, nonetheless come to significantly disparate conclusions when trying to rank their choices on a magnitude scale without a modulus. ${ }^{156}$ This Part argues that, under the current system, juries or judges assessing whether a plaintiff poses a significant risk are using an anchorless magnitude scale of sorts. It follows that in the absence of a standard modulus or benchmark these decisions will be both inconsistent and inaccurate.

Psychologists refer to two types of scales: category and magnitude. ${ }^{157}$ "Category scales are bounded and anchored in verbal descriptions at both ends. . . . Magnitude scales, by contrast, are unbounded and are defined by a meaningful zero point." 158 Typically, users of magnitude scales define a modulus by requiring subjects to assign a value to a standard stimulus. ${ }^{159}$ This value is defined as the modulus. The subject then evaluates other stimuli in comparison to that modulus. ${ }^{160}$ When magnitude scales are used without a defined modulus, "different respondents spontaneously adopt different moduli... . [O]ne observer may assign a judgment of 200 to a stimulus that another observer rates as 10 . If the first observer now assigns a rating of 500 to a new stimulus, we may expect the second to assign to that stimulus a value of roughly $25 . " 161$

Decisions based on magnitude scales typically exhibit a high degree of

155. Generally, a modulus is "[a] quantity that expresses the degree to which a substance possesses a property." The AMERICAN HERITAGe DictionARY OF THE ENGLiSH LANGUAGE 1162 (3d ed. 1992). In psychology, a modulus is a value assigned to a standard stimuli. See Sunstein, Kahneman \& Schkade, supra note 49 , at 2106 . This value enables a comparison of individuals' rankings of variables on a magnitude scale.

156. The problem of scaling without a modulus has previously been applied to the legal context, most notably in Sunstein, Kahneman \& Schkade, supra note 49 , at 2106 , but also, for example, in Kahneman et al., supra note 51, at 6.

157. Sunstein, Kahneman \& Schkade, supra note 49 , at 2106.

158. Id.

159. See id.

160. See id.

161. Id. at 2106-07. The notion that individuals adopt their own moduli when one is not provided for them is consistent with the anchoring heuristic. The anchoring heuristic refers to decision makers' tendency to "make probability judgments on the basis of an initial value, or 'anchor,' for which they make insufficient adjustments." BEHAVIORAL LAW AND ECONOMICS, supra note 149, at 5. When individuals make judgments based on an initial value as an anchor, and the anchor is arbitrary or inaccurate (and it often is), risk determinations will be similarly arbitrary or inaccurate. See id. Empirical evidence from the study of juries' damage awards demonstrates that decision makers assigning values without an anchor come to arbitrary and irrational conclusions. See id. 
variability. ${ }^{162}$ The lack of a modulus significantly compounds this variability. "Magnitude scaling without a modulus produces extremely large variability in judgments of any particular stimulus, because of arbitrary individual differences in moduli." ${ }^{163}$

An example from the literature on jury determinations of punitive damages illustrates the problem. In empirical studies on monetizing punishment, measuring how people rank severity of wrongdoing on a moral scale and how much they want to punish people on a monetary scale, participants rank moral severity with substantial uniformity. ${ }^{164}$ Moral judgments are extremely consistent across every demographic. ${ }^{165}$ In contrast, with respect to dollars, disagreement is substantial. ${ }^{166}$ One account offered by psychologists and lawyers to explain this phenomenon is the modulus problem: people do not have a standard to figure out what to compare their numbers to when the number scale is too large. Without a modulus, people do not know what dollars mean.

The task of assigning values to probabilities may require using a magnitude scale. The zero point on a magnitude scale for probability is zero percent probability and every number between zero and 100 percent (absolute probability) is on the scale. Unlike jury determinations of punitive damage awards, which involve mapping punitive intent onto a dollar scale based exclusively on magnitude, the ADA is a bit of a hybrid. At first cut, the significant risk determination might seem to involve something more like a category scale, relying on verbal descriptions. One might argue that a jury never needs to resort to numbers because they can simply rely on categories such as "direct threat" and "no direct threat," "significant" and "insignificant." On closer look, however, the significant risk determination inevitably requires numerical, magnitude scaling in order to operationalize the "probability" variable. ${ }^{167}$ In other words, because determining whether a given risk is "significant" requires a measure of potential harm and probability, ${ }^{168}$ decision makers, either implicitly or explicitly, are forced to "map" their intuitions onto a numeric scale. The issue is whether they

162. Sunstein, Kahneman \& Schkade, supra note 49, at 2106.

163. Id. at 2107 .

164. See id. at 2074 (concluding that, "at least in ... personal injury cases.... people's moral judgments are remarkably widely shared").

165. See id. at 2074.

166. See id. at 2074 ("[P]eople have a great deal of difficulty in mapping such [moral] judgments onto an unbounded scale of dollars. Shared moral judgments but erratic, unpredictable, and arbitrary awards, possibly even meaningless awards, are a potential product of this difficulty.").

167. "The 'significance' of risk inescapably involves a judgment about the probabilities of harm." Estate of Mauro v. Borgess Medical Ctr., 137 F.3d 398, 409 (1998) (Boggs dissenting). Even if we think decision makers are better off relying exclusively on categories, the statute does not permit this path. Rather, the statute explicitly requires decision makers to address probability. See supra notes 37-39.

168. This is both a matter of logic and a matter of law, see supra note 38 . 
accomplish this task consistently and accurately. The current framework's lack of a modulus for the probability scale suggests that they do not. The lack of a modulus helps explain why ADA direct threat determinations are both inconsistent and inaccurate.

First, requiring decision makers to map their intuitions about whether a given threat poses a significant risk onto a scale without a modulus yields inconsistency. The ADA has no modulus for decision makers to discipline their inquiry. Much like the example of punitive damage awards, where there is moral consensus but monetary discensus, in direct threat determinations we can expect consensus on the ranking of certain risks ${ }^{169}$ but discensus on whether such risks qualify as "significant." For example, decision makers might consistently agree that a blind bus driver is a larger risk than a hearing impaired bus driver who, in turn, is a larger risk than a diabetic bus driver. Decision makers are likely to disagree, however, about which of these plaintiffs poses a significant risk. In all three instances, the potential harm is the same-a bus accident. What differs is the probability of the harm's occurrence and it is on this metric that the lack of a modulus creates problems. This highly stylized example focuses on a comparison of only three potential plaintiffs. When one considers the countless disability/workplace combinations, it becomes apparent why determinations lack consistency. Because decision makers do not know what "significant" means, their decisions will be all over the map.

Because determining whether an individual poses a significant risk involves "sizing up" the danger a given plaintiff poses, these calculations are particularly prone to inconsistency. Comparing an individual who poses a significant risk to an individual who poses an insignificant risk is a difference in degree, not a difference in kind. Without some metric or modulus to guide the inquiry, decision makers are left to apply a list of relevant factors to get to the "correct" outcome. Those who favor rules over standards might be particularly worried by such an open-ended calculus both because the thing to be decided (significant risk) is not pinned down, and the way it is to be decided (a list of factors) seems equally unprincipled.

Second, mapping intuitions about a risk's significance onto a scale without a modulus results in inaccuracy. Using an unbounded probability scale without a modulus - where direct threat determinations are made on a case-by-case basis under conditions of uncertainty-leads to a high likelihood of inaccurate judgments. Juries are particularly prone to this type of error because they are not aware that it is occurring and because the oneshot nature of their involvement ensures that they cannot learn to account for this error. Even if decision makers can scale risks qualitatively, by

169. The expectation of consensus with regard to ranking threats to workplace safety was supported by an informal survey of University of Chicago Law Students $(\mathrm{N}=24)$. 
ranking them from extremely insignificant to extremely significant, with some degree of consistency, they will be unlikely to reach accurate decisions regarding when those risks move from the significant side of the line to the insignificant side of the line-the crucial determination under the ADA. With probabilities ranging from zero to 100 percent, and every fraction in between, massive divergence is quite likely even if decision makers fundamentally agree on some basic premises.

Because the requisite probability needed to classify a risk as significant is undefined, juries and judges use their own rules of thumb. For instance, a decision maker might determine that a $1,0.1$, or 0.001 percent probability of a given harm is sufficient to count as significant. The decision maker might make this determination implicitly, by lumping the probability inquiry and analysis of the potential harm together. This type of decision making is illustrated by Onishea and Montalvo, where the court held that any probability was sufficient because the magnitude of the harm was overwhelmingly large. Alternatively, decision makers might explicitly address the probability variable but still come to inaccurate conclusions when they conflate probability and harm. Because probability is often not explicitly addressed and because, even when it is addressed it is often conflated with the magnitude of the harm, decision makers have no modulus for what counts as a sufficient probability. Accordingly, decision makers assign their own moduli and inconsistent and inaccurate direct threat determinations result.

\section{B. Outcome-Dependent Probability Weighting}

The conventional economic assumption, captured in expected utility models, is that individuals value prospective courses of action by considering two variables: outcome and probability. ${ }^{170}$ Although the terminology may appear exotic, the idea is simple-when evaluating how good or bad, risky or not risky, valuable or not valuable, a prospective outcome is, rational actors consider both the potential outcome and its likelihood. For instance, we value a 50 percent chance of winning $\$ 100$ twice as much as we value a 25 percent chance. ${ }^{171}$

An important, additional nuance of the conventional economic

170. See George F. Loewenstein et al., Risk as Feelings 26 (Draft 10, Oct. 17, 1999) (on file with author) (noting that "in the expected utility model, the value of a prospect is equal to the sum of the utilities of outcomes that could be experienced, weighted by their likelihood of occurrence").

171. The simple computation is that $100 \times .50=50$ and $100 \times .25=25$, and, of course, 50 is twice as much as 25 . A recent, informal study $(\mathrm{N}=19)$ confirms the assumption that, for some category of outcomes, decision makers respond consistently with the expected utility model. Survey participants' (students at the University of Chicago Law School) median willingness to pay to avoid losing $\$ 100$ exactly tracked the change in the probability of losing the $\$ 100$. See Brian S. Prestes, OutcomeDependent Probability Weighting 7 (Mar 3, 2001) (unpublished manuscript on file with author). 
assumption is that individuals weight probability independent of the outcome under consideration: the relevance of probability does not depend on the content of the outcome being considered. This is not to say that rational decision makers accept equal probabilities of different outcomes; surely a 1 percent risk of fatality is still greater than a 10 percent risk of losing, say, $\$ 100$. The point is that, for both scenarios, individuals consider probability and discount the potential harm accordingly. In other words, on the conventional view, decision makers are equally sensitive to probability regardless of the outcome being considered. Accordingly, decision makers should respond similarly to similar changes in probabilities. If the probability of a given harm is cut in half, then individuals' desire to avoid the harm should decrease by a similar margin independent of the content of the potential outcome.

Recent evidence, however, demonstrates that the conventional economic assumption of sensitivity to probability independent of potential outcome does not hold. Scholars have demonstrated that, for some category of outcomes, individuals in fact do not perform evaluations based on a straightforward outcome/probability calculation. Instead, the relevance of probability appears to depend on the outcome under consideration. In a recent paper, Lowenstein and his co-authors argue that, for "emotion laden" end states, "[c]hanges in probability within some broad midrange of values have little effect on anticipatory emotions." 172 The authors explain that "[o]ne's mental image of what it would be like to win the State lottery, for example, is likely to be about the same, whether there is a one in tenmillion chance of winning or a one in ten-thousand chance of winning."173

Earlier psychophysical studies also confirm a species of this result. These studies demonstrate that individual's physiological reaction to receiving a painful electric shock varied little based on the probability of actually receiving the shock. ${ }^{174}$ "[T] was enough to arouse subjects, and the precise likelihood of being shocked had little impact on their arousal level." 175

Most interestingly, in a recent paper by Rottenstreich and Hsee, the authors "asked participants to indicate a cash certainty equivalent for avoiding an undesirable outcome that occurred with different levels of probability." 176 The undesirable outcomes presented to the participants were a loss of $\$ 20$ and a painful electric shock. The authors found that for the "pallid" outcome (losing \$20), participants responded consistently with the expected utility calculation. That is, the respondents were sensitive to not

\footnotetext{
172. Loewenstein et al., supra note 170 , at 26 .

173. Id.

174. Id. at $26-27$.

175. Id. at 27.

176. Id. at 28 (describing Rottenstreich and Hsee's findings).
} 
only the outcome but also to the probability of its occurrence. For the more "emotion laden" outcomes (receiving an electric shock), however, the authors found that respondents' willingness to pay (WTP) deviated substantially from the expected utility predictions. In other words, dramatic decreases in the probability of receiving an electric shock did not result in concomitant decreases in WTP. ${ }^{177}$ Lowenstein et al., interpret these findings as evidence that "the impact of probability depends strongly on the nature of the outcome. The probability weighting function is flatter (i.e., more overweighting of small probabilities) for vivid outcomes that evoke emotions than for pallid outcomes." 178

So how is all of this relevant to direct threat determinations under the ADA? The ADA requires decision makers to evaluate whether plaintiffs pose a direct threat. The law specifically requires decision makers, consistent with the expected utility model, to consider both outcome and probability. ${ }^{179}$ Relevant factors for determining whether a plaintiff poses a direct threat include: "(1) The duration of the risk; (2) The nature and severity of the potential harm; (3) The likelihood that the potential harm will occur; and (4) The imminence of the potential harm." ${ }^{80}$ Factors one, two, and four require assessment of the potential outcome. Factor three requires analysis of the probability of that outcome.

The fact that decision makers in some instances engage in outcomedependent probability weighting may create problems for a law that requires individuals to consider both probability and outcome. Although the law at no point requires that decision makers be equally sensitive to probability for all categories of disability, the fact that decision makers exhibit outcome-dependent sensitivity to probability creates inconsistency and inaccuracy. Although it is perfectly reasonable to tolerate lower probabilities of more severe outcomes, inconsistency and inaccuracy arise when sensitivity to probability depends on the outcome being evaluated. Consider the following illustrations.

HIV is "[p]erhaps the most stigmatizing condition in contemporary society." 181 The disease evokes a highly emotional response. Juries or judges engaging in outcome-dependent probability weighting will be less sensitive to probability when evaluating the risk posed by an HIV positive individual. Accordingly, juries and judges will be more likely to find that these individuals pose a direct threat to others regardless of the probability

177. Id.

178. Id.

179. See supra text accompanying note 38 .

180. 29 C.F.R. $\$ 1630.2(r)$; see Sch. Bd. of Nassau County v. Arline, 480 U.S. 273, 288 (1987) (articulating a similar test).

181. WeINER, supra note 68 , at 115 . This point is amplified supra notes $68-72$ and accompanying text. 
of any real harm occurring.

Outcome-dependent probability weighting may help explain the reasoning in Onishea. ${ }^{182}$ By rejecting the plaintiff's expert testimony, which empirically demonstrated that "incidents of HIV transmission in many activities are rare or virtually unknown," 183 in favor of the defendant's testimony asserting that "HIV transmission is theoretically possible, even if not documented," 184 the court illustrated a decision making process insensitive to probability. Although it is reasonable to be weary of even low probabilities of HIV transmission, the court took the gravity of the potential outcome as justification to analyze probability almost as if it were irrelevant.

Cases involving the mentally ill disabled also illustrate the potential inconsistency and inaccuracy resulting from outcome-dependent probability weighting. Mental illness generally evokes a visceral response from decision makers. "Often, stereotyping and the resultant stigmatization are even more invidious for individuals with psychiatric, as opposed to physical, disabilities." 185 Therefore, juries or judges evaluating the risk posed by a schizophrenic, for instance, might be more likely to discard probability (contrary to the ADA's mandates), focus on outcome, and find the schizophrenic plaintiff to pose a direct threat. This prediction is consistent with the fact that schizophrenics have one of the lowest benefit rates of all "successful" ADA plaintiffs. ${ }^{186}$

In contrast to the cases involving plaintiffs with emotion-laden disabilities such as HIV and mental illness, we might expect juries to treat differently plaintiffs with more pallid disabilities, such as back injuries, vision impairment, and asthma. Decision makers are more worried about those with psychiatric disabilities than about those with physical disabilities: " 47 percent of those surveyed were very comfortable with people who are blind, and 59 percent of those surveyed were very comfortable with people who use a wheelchair, while only 19 percent of the people surveyed were very comfortable with people with mental illness." 187

The fact that decision makers fear those with psychiatric disabilities more than they fear those with physical disabilities might be unobjectionable if this fear were a result of a more textured, nuanced understanding of the various risks posed by individuals whose disabilities

182. See supra notes 75-84 (discussing Onishea).

183. Onishea v. Hopper, 171 F.3d 1289, 1293 (11th Cir. 1999).

184. Id. at 1294.

185. Danforth, supra note 23, at 664 .

186. Moss, supra note 65 , at 133.

187. Miller, supra note 14 , at 12 n.7, citing National ORganization ON Disability, PUBLIC ATtitudes Toward People With Disabilities (1991) (survey conducted by Louis Harris and Associates, Inc.). 
were different in kind. But, in fact, in the general run of cases, the mentally ill are no more likely to pose a significant risk than those with physical disabilities: "The fear with which some people regard all psychiatric patients is completely out of proportion to the small group representing an authentic danger to others." 188 The difference between decision makers' reaction to those with psychiatric disabilities and those with physical disabilities embodies our society's "long history of assuming that the mentally ill are dangerous." 189 This is the kind of misinformed consideration the ADA was meant to prohibit rather than embrace.

The difference between decision makers' reaction to psychiatric disability (visceral) and their reaction to physical disability (pallid) might explain why plaintiffs with back injuries, vision impairment, and asthma, for example, have some of the highest benefit rates of successful ADA plaintiffs. ${ }^{190}$ Because these plaintiffs pose more pallid risks, decision makers treat them more like Rottenstreich and Hsee's \$20 dollar scenarioindividuals judge the risks they pose by carefully considering probability and as a result these individuals receive treatment that is both different and better (in the sense that it is more accurate) than their counterparts whose disabilities evoke more emotional, visceral reactions.

All of this is a problem if we think that decision makers determining whether a plaintiff poses a significant risk should be making this determination based on objective evidence falling under the categories made relevant by the Arline factors. That is, if we think individuals posing equivalent objective risks should be treated similarly, and that the type of disability should be relevant only insofar as it bears on actual risk, then we should seek a policy change that addresses outcome-dependent probability weighting. Furthermore, if we think that unfounded, subjective fears have no place in the direct threat inquiry, then we should seek a solution that moves away from the type of unanchored inquiry that allows these misconceptions to creep in.

Individuals are likely to discard probability when considering cases of emotion-laden disabilities but be sensitive to probability when considering more pallid disabilities. The ADA, however, prefers that decision makers' considerations of probability not be based on subjective fears arising out of

188. Harold I. Kaplan \& Benjamin J. Sadock, Synopsis of Psychiatry: Behavioral SCIENCES, CliniCAL PSYCHIATRy 561 (6th ed. 1991). "[M]any studies demonstrate that employers have strong negative perceptions of persons known or thought to have a mental illness." Jean Campbell \& Caroline L. Kaufman, Equality and Difference in the ADA: Unintended Consequences for Employment of People with Mental Health Disabilities, in MenTal. Disorder, WORK DisabILITY, AND THE LAW 221, 228 (Richard J. Bonnie \& John Monahan eds., 1997).

189. John Monahan, “A Terror to Their Neighbors": Beliefs about Mental Disorder and Violence in Historical and Cultural Perspective, 20 BULL. AM. ACAD. PSYCHIATRY \& L. 191, 191-95 (1992); Danforth, supra note 23, at 685.

190. Miller, supra note 14 , at 12. 
irrelevant differences in plaintiffs' disabilities. Therefore, requiring juries to make explicit findings of probability, deferring to experts who give appropriate weight to probability, or relying on predetermined grids might yield outcomes more consistent with our ultimate goal of rational decisionmaking if these proposals help ensure more consistent sensitivity to probability.

\section{Focus on the Worst-Case Scenario}

People's responses to risk are not always rational. Sometimes "individuals respond in an alarmist manner to increases in the risks they face even though these increases may be rather small." ${ }^{191}$ But individuals do not simply overestimate all risks. "A widely cited result in the risk perception literature is that individuals assessing risks of fatality overassess the risks of low-probability events (e.g., smallpox, tornadoes, botulism) and underestimate the risks of high-probability events (e.g., diabetes, heart disease, and stroke)."192 In addition, when decision makers are presented with divergent risk estimates, as would be the case in a trial, individuals are more sensitive to the high risk estimate. ${ }^{193}$ That is, people are likely to assume the worst when presented with both low and high risk estimates.

Because direct threat determinations are made according to the EEOC's four-factor test, ${ }^{194}$ which does not incorporate statistical benchmarks, it is likely that a presumption toward worst-case scenarios tilts the judgments. ${ }^{195}$ By not telling decision makers what level of probability is required to find a given harm "significant," the ADA leaves the probability inquiry unguided and prone to error. This tendency is troubling. Risk-averse judgments impact negatively on the ADA's goal of integrating the disabled into the workplace to the extent that the disabled are denied employment based on a successful direct threat defense.

Reliance on worst-case risk assessment is even more troubling to the extent that, by definition, worst-case scenarios do not reflect the most likely scenario: The disabled will be barred from the workplace based on an implicit, but nonetheless statistically inaccurate, determination that even if

191. VISCUSI, supra note 60 , at 139.

192. Id. at 102. "This pattern of underestimation and overestimation seems to hold true across a range of different cultures and different times." Christine Jolls, Behavioral Economic Analysis of Redistributive Legal Rules, in BEHAVIORAL LAW AND ECONOMICS, supra note 149, at 290; see Vincent T. Covello \& Branden B. Johnson, The Social and Cultural Construction of Risk: Issues, Methods, and Case Studies, in The Social and Cultural Construction of RisK: EsSAYs on Risk SElection AND PERCEPTION vii-ix (Branden B. Johnson \& Vincent T. Covello eds., 1987).

193. See W. Kip Viscusi, Alarmist Decisions with Divergent Risk Information, 107 ECON. J. 1657, 1668 (1997).

194. See supra text accompanying note 38 .

195. See supra note 193. 
they pose a small risk, the risk is still too great. ${ }^{196}$ Even if risk conservatism is an explicit agency goal, such conservatism should be implemented through "a more rigorous procedure ... than the current series of ad hoc adjustments with unknown consequences." 197

Furthermore, a focus on the worst-case scenario may be particularly detrimental to individuals posing the kind of risk more likely to be overestimated. For instance, individuals tend to overestimate the risk posed by those with HIV by assuming that the probability of transmission is higher than it really is or by ignoring the probability altogether and focusing on the harm of transmission. Similarly, individuals tend to overestimate the danger posed by the mentally ill, giving in to stereotypes and ignoring the fact that the vast majority of the mentally ill pose no danger whatsoever. ${ }^{198}$

We might also worry that the "better safe than sorry approach"199 reflects an unwarranted assumption that potential losses outweigh potential gains, even when the magnitude of such effects is the same. ${ }^{200}$ In the case of the disabled, juries and judges may mistakenly determine that the accident risk posed by disabled employees outweighs the potential gains for society and the employed disabled when the magnitude of the costs and the benefits is the same or even when the benefits appreciably outweigh the costs.

Such a policy might reflect decision makers' tendency to put a higher weight on false negatives than on false positives. In other words, they might assign greater weight to potential losses from mistakenly allowing the disabled to work (when they actually do pose a direct threat) than from mistakenly barring the disabled from employment (when they do not, in fact, pose a threat). This overweighing of false negatives can be explained by the likelihood that "false negatives" are more visible than "false positives" and because false negatives result in more catastrophic harm. ${ }^{201}$ In either scenario, the benefits of employing the disabled are underestimated while the harms are overestimated and the mandate of the

196. See P. Christen Dockins, James T. Hamilton \& W. Kip Viscusi, Assessing Conservatism in Individual Risk Estimates, in JAMES T. HAMILTON \& W. KIP VISCUSI, CALCULATING Risks? ThE

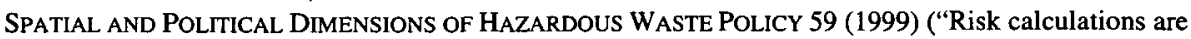
subject to considerable uncertainty and variability. Governmental risk estimates have typically treated such uncertainties conservatively through the assumptions and default positions mandated by policy makers. In effect worst-case scenarios assume a more prominent role than more realistic risk assessments. If our objective is to save the greatest expected number of lives, however, the mean risk should be our guide.").

197. Id. at 59 (describing the worst-case scenario bias in the context of hazardous waste cleanup and remediation).

198. See infra Part IV.B.

199. Dockins, Hamilton \& Viscusi, supra note 196, at 60.

200. This assumption is consistent with the concept of loss aversion-people are roughly twice as displeased by losses as they are with gains of equivalent magnitude. Sunstein, Introduction, in BEHAVIORAL LAW AND ECONOMICS, supra note 150, at 5.

201. See James E. Krier, Risk and Design, 19 J. LEGAL STUD. 781 (1990). 
ADA is thwarted to the extent that disabled individuals are unnecessarily excluded from the workplace.

Having demonstrated that current direct threat determinations are inconsistent and inaccurate and having offered explanations for this inaccuracy that are tied to the unanchored nature of the current framework, the following Part offers a proposal for better disciplining direct threat determinations.

$\mathrm{V}$.

\section{Alternative Means of Direct Threat ANALYsis}

Numerical benchmarks should be implemented to better discipline significant risk decisions under the ADA. The numerical benchmarks under the Occupational Safety and Health Act serve as empirical evidence supporting the feasibility of such a system in the ADA regime. Numerical benchmarks would result in a more anchored inquiry addressing the modulus problem, reducing outcome-dependent probability weighting, curtailing reliance on worst-case scenarios, and cabining the effects of discrimination. Ultimately, more consistent and accurate direct threat determinations would result and this outcome, in turn, would advance the antidiscriminatory aim of the ADA.

This Part begins by establishing that it is within the bounds of the ADA to use statistical benchmarks in direct threat analysis. It then describes OSHA's statistical benchmarks and concludes by arguing that similar benchmarks would improve the consistency and accuracy of decisions under the ADA.

\section{A. The Text of the ADA Permits Alternatives to the Current Mode of Direct Threat Analysis}

Are there multiple reasonable and acceptable interpretations of what constitutes a significant risk? One might argue that the statutory text demands an inquiry more disciplined than the current approach in order to give meaning to the term "significant risk." On the other hand, one might object to the statistical benchmarks proposal on the grounds that the statutory text does not expressly demand a more precise and disciplined inquiry. If the ADA were clearly to prohibit statistical benchmarks then there would already be one strike against the proposal. The point here is to establish that the law does not prohibit using statistics in this context.

The text of the ADA neither expressly requires nor forbids the use of statistical anchors when evaluating whether an individual poses a direct threat. The ADA simply defines a direct threat as a significant risk. In other 
words, Congress does not appear to have "directly addressed the precise question at issue." ${ }^{202}$ To the contrary, Congress has "explicitly left a gap for the agency to fill." ${ }^{203}$ The gap is explicit in the sense that the ADA makes the EEOC responsible for promulgating regulations to give meaning to the provisions of Title I. ${ }^{204}$

Given this statutory silence, the appropriate question is whether a statistical benchmarks requirement, of any sort, is "a permissible construction of the statute." 205 In other words, whether statistical benchmarks are "reasonable."

There is little reason to believe that a reviewing court would find that EEOC use of statistical benchmarks is an unreasonable or impermissible construction of the ADA's direct threat provision given that such an interpretation appears consistent with the text of the Act, its purpose, ${ }^{206}$ and existing administrative guidelines. ${ }^{207}$ Statistical benchmarks are likely to make the current four-prong significant risk determination mandated by the EEOC more consistent, determinant, and meaningful. ${ }^{208}$

\section{B. OSHA's Interpretation of "Significant Risk"}

The significant risk standard, central to the ADA's direct threat defense, is also a baseline used to justify regulation under the Occupational Safety and Health Act. OSHA and courts overseeing OSHA's attempts to regulate workplace health and safety have developed a set of numerical benchmarks setting a floor and ceiling for what constitutes a significant risk. In particular, they have articulated explicit probability levels required to show that a risk is significant. Applying these benchmarks, courts have held that a finding of significant risk presumptively justifies regulation under the Occupational Safety and Health Act and that an absence of significant risk precludes regulation.

The Occupational Safety and Health Act delegates authority to the Secretary of Labor to promulgate occupational safety and health

202. Chevron U.S.A., Inc. v. Natural Resources Defense Council Inc., 467 U.S. 837, 843 (1984).

203. Id.

204. See supra note 36 and accompanying text.

205. Chevron, 467 U.S. at 843

206. See supra note 56 and accompanying text.

207. Note that " $[\mathrm{t}]$ he court need not conclude that the agency construction was the only one ... or even the reading the court would have reached." Chevron, 467 U.S. at 843 n.11. Unless "arbitrary, capricious, or manifestly contrary to the statute," id. at 844 , courts would give an EEOC regulation requiring the use of statistical benchmarks controlling weight.

208. Compare the argument for deference to EEOC use of statistical benchmarks to the argument, accepted by the courts, for upholding the EEOC's mandate requiring individualized assessments of plaintiffs alleged to pose a direct threat. See Kapche v. City of San Antonio, 176 F.3d 840, 844, n.22 (5th Cir. 1999) (citing Chevron as the basis for deferring to the EEOC's individualized inquiry requirement). 
standards. ${ }^{209}$ Section 3(8) of the Occupational Safety and Health Act defines occupational safety and health standards: "The term 'occupational safety and health standard' means a standard which requires conditions, or the adoption or use of one or more practices, means, methods, operations, or processes, reasonably necessary or appropriate to provide safe or healthful employment and places of employment."210

The Court, in Industrial Union Department, AFL-CIO v. American Petroleum Institute (the Benzene case), ${ }^{211}$ held that when promulgating occupational safety and health standards under the Occupational Safety and Health Act, ${ }^{212}$ a finding of "significant risk" is a prerequisite to regulation. ${ }^{213}$ "[Section] 3(8) . . requires the Secretary, before issuing any standard, to determine that it is reasonably necessary and appropriate to remedy a significant risk of material health impairment."214 The Court stated that "before he can promulgate any permanent health or safety standard, the Secretary is required to make a threshold finding that a place of employment is unsafe-in the sense that significant risks are present and can be eliminated or lessened by a change in practices." 215 While OSHA has "no duty to calculate the exact probability of harm," 16 OSHA "necessarily seeks to quantify the risk posed by each toxic threat." ${ }^{217}$

Benzene also took the first step toward establishing a benchmark for the probability level required for a potential harm to constitute a significant risk. $^{218}$ The Court held that a $1 / 1,000$ risk of death is significant; $;{ }^{219}$ it stated that "[i]f the odds are one in a thousand that regular inhalation of gasoline vapors that are $2 \%$ benzene will be fatal, a reasonable person might well consider the risk significant and take appropriate steps to decrease or

209. Occupational Safety and Health Act of 1970, 84 Stat 1590, 29 U.S.C. $\$ \S 651-67.8$ (1994 \& Supp II 1996).

210. 29 U.S.C. $\$ 652(8)$.

211. 448 U.S. 607 (1980).

212. 29 U.S.C. $\S \S 651-678$. Additional requirements for regulating toxic materials or harmful physical agents are set forth in $\S 6(\mathrm{~b})(5)$ of the Act. 29 U.S.C. $\S 655$. While Benzene dealt with regulation of a toxic substance, the "significant risk" requirement applies to any occupational safety and health standard promulgated by OSHA. See Benzene, 448 U.S. at 607.

213. Benzene, 448 U.S. at 652.

214. Id. at 639 (emphasis added).

215. Id.

216. Id. at 655 .

217. Int'l Union v. Pendergrass, 878 F.2d 389, 392 (D.C. Cir. 1989) (recognizing court's duty to defer to OSHA's scientific/statistical risk determinations but finding OSHA's estimates "all over the lot").

218. Benzene, 448 U.S. at 655.

219. Notably, the Court also held that "[i]t is the Agency's responsibility to determine, in the first instance, what it considers to be a 'significant' risk." Id. This lends support to the argument that the EEOC has the requisite discretion to modify its definition of "significant risk," see infra Part V.A, especially given the argument that the proposed statistical benchmarks are supplements to, rather than inconsistent with, the current four factor test. 
eliminate it." 220 OSHA agreed and subsequently adopted the "one in a thousand" standard "as a policy norm, at least in the sense of believing that it must regulate if it finds a risk at the $1 / 1000$ level." 221

The numerical benchmark, above which a risk is considered presumptively significant, was further developed in Building \& Construction Trades Department, AFL-CIO v. Brock. ${ }^{222}$ In Brock, the D.C. Circuit held that a lifetime risk of death of over $1.64 / 1,000$, caused by workplace conditions, counts as significant. ${ }^{223}$ If a risk of $1.64 / 1,000$ or greater is established then regulation is deemed presumptively desirable. ${ }^{224}$

At the other end of the spectrum, the Benzene Court noted that a risk of one in a billion (from drinking a glass of water) does not count as significant. ${ }^{225}$ Similarly, OSHA has decided that a risk of 0.6 in 100,000 (the equivalent of six in one million) "may be approaching a level that can be viewed as safe." 226

These holdings establish a rebuttable floor and ceiling for what counts as a significant risk under the Occupational Safety and Health Act. Any risk of death greater than or equal to $1 / 1,000$ is presumptively significant. Likewise, any risk of death less than or equal to six in one million (or $0.006 / 1,000)$ is presumptively insignificant. Risks falling in between these two poles are in a gray area where they are neither presumptively significant nor presumptively insignificant but, rather, subject to a case-bycase inquiry without a thumb on the scale.

To some readers, the specific numbers adopted by OSHA may appear haphazard. To others, the numbers may appear reasonable but hardly relevant to the ADA-mandated inquiry. But what has been established in this section is that the significant risk standard, interpreted under a statute similar to the ADA in the sense that the relevant parts of both statutes deal with workplace risks, has been disciplined using explicit statistical benchmarks. The point is not that OSHA's regime should be unthinkingly mapped onto the ADA inquiry. The OSHA analogy should merely be taken as evidence that numerical benchmarks have been implemented in one context and, for this reason, could be implemented in another. The

220. Benzene, 448 U.S. at 655.

221. Benzene, 878 F.2d at 392; see also AFL-CIO v. OSHA, 965 F.2d 962, 973 \& n.15 (11th Cir. 1992) (documenting OSHA's incorporation of the one in a thousand standard); see, e.g., Public Citizen Health Research Group v. Tyson, 796 F.2d 1479, 1502-03 (D.C. Cir. 1986) (12-23 excess deaths out of 10,000 workers is a significant risk.); Building. \& Constr. Trades Dep't, AFL-CIO v. Brock, 838 F.2d 1258,1265 (D.C. Cir. 1988) ("risk of 1.64 excess mesothelioma deaths per 1000 . . . expressly found significant").

222. 838 F.2d at 1265 (D.C. Cir. 1988).

223. See id.

224. See id.

225. See Benzene, 448 U.S. at 655 .

226. Occupational Exposure to Formaldehyde, 52 Fed. Reg. 46,168, 46,234 (1987). 
following section defends statistical benchmarks for the ADA's direct threat inquiry and Part V.C.3 explicitly addresses the criticism that a statistical inquiry may be no more consistent than the current ad-hoc approach.

\section{Statistical Benchmarks Could Improve Direct Threat Inquiries}

\section{Statistical Benchmarks and the ADA}

A set of numerical benchmarks, inspired by the benchmarks established by the courts and developed by OSHA, could be implemented to better discipline significant risk decisions under the ADA.

OSHA's numerical benchmarks serve as empirical evidence for the feasibility of such a system under the ADA regime. First, under the Occupational Safety and Health Act, decision makers are interpreting the same language as used in the ADA - "significant risk." Second, significant risk determinations under the Occupational Safety and Health Act are made in a similar context to significant risk assessments under the ADA. Both involve an analysis of workplace risks. These similarities suggest that the system of numerical benchmarks used under the Occupational Safety and Health Act could serve as a conceptual starting point for developing benchmarks that would improve the ADA inquiry.

The following discussion elaborates on a number of proposals, all involving statistical benchmarks of some sort, that might improve the consistency and accuracy of the direct threat inquiry. The discussion begins with the least drastic proposal and moves toward more ambitious reforms.

Proposal One: Simple Numbers. Perhaps the least ambitious proposal for injecting statistics into the direct threat inquiry is to provide the decision maker with a standard value representing the probability required to make a given plaintiff a direct threat. To illustrate, the EEOC might specify that a one in one hundred thousand probability of death qualifies as a presumptively significant risk or that a one in one million probability of transmitting HIV is presumptively significant. The exact numbers are not particularly important here although getting them right would be relevant to successfully implementing the proposal.

These guidelines, providing decision makers with benchmarks illustrating both the requisite probability and the relevant outcome needed to qualify a risk as significant per se, are similar to the D.C. Circuit's holding in Brock that a lifetime risk of death of over 1.64/1,000, caused by workplace conditions, counts as significant. ${ }^{227}$

Statistical benchmarks of this sort would not require that the direct 
threat decision be taken out of the hands of the jury, rather, these benchmarks could be provided to the jury in the form of a jury instruction. These benchmarks would then leave the probability and magnitude of a given threat to the parties to prove by means of existing evidence; the statistics would merely describe in explicit terms what the parties must ultimately demonstrate in order to prevail. Benchmarks would likely affect the way parties argue by enhancing the legal relevance and persuasive value of statistical evidence. When applied to the non-litigation setting, for example, when the EEOC is evaluating the strength of a claim, the benchmarks could serve as the relevant baseline by which to objectively evaluate the strength of a potential direct threat defense.

Proposal Two: Bounded Scales. A second proposal, slightly more ambitious than the first, would be to measure whether a risk is significant by using a bounded numerical scale: for example, by requiring decision makers to rank the probability of a potential harm coming to fruition by assigning a number from one to ten. Individuals could be required to rate the relevant Arline factors on a bounded numeric scale, assigning a separate value to the severity of the potential outcome, its probability, imminence, etc.

Again, this proposal need not take the direct threat decision out of the jury's hands, although it would constrain the jury in a beneficial way. By requiring the jury to "map" their assessments of probability and outcome onto numeric scales, we might ensure that juries give independent consideration to both variables. By using a bounded numeric scale instead of requiring juries to consider probabilities in percentage terms, we could avoid the problems associated with mapping probability judgments onto unbounded scales without a modulus. The judge, an administrative body, or some other kind of review panel could translate the jury's ratings into a finding of direct threat or no direct threat based on some predetermined weighting of the factors.

Proposal Three: Experts? One proposal that has been advocated elsewhere is the use of medical review panels to evaluate whether a party poses a direct threat. ${ }^{228}$ " $[R]$ egulations should provide that whenever an employer seeks to exclude an [individual allegedly posing a direct threat] the employer can do so if (1) it has retained a qualified, independent physician ... and (2) that physician analyzes each of the Arline factors and concludes . . . that the individual poses a 'direct threat." 229

Although the statistical benchmarks proposals advocated in this Article

228. See Jeffrey A. Van Detta, "Typhoid Mary" Meets the ADA: A Case Study of the "Direct Threat" Standard Under the Americans with Disabilities Act, 22 HARV. J.L. \& PUB. POL'Y 849, 949 (1999).

229. Id. at 953-54. 
might in some ways by more easily implemented by experts than by jurors and judges, it is not clear that simply transferring the direct threat decision to medical experts (that is, doctors) will make things much better.

In other words, expert assessments, even if necessary, are not sufficient to reduce inconsistency and inaccuracy. Doctors are vulnerable to many of the same cognitive errors and biases as the general public. ${ }^{230}$ In a recent paper, Professors Meadow and Sunstein present evidence that doctors, much like juries and judges, make significant errors in evaluating probabilities. ${ }^{231}$ For example, the authors find that doctors tend to overestimate the ordinary standard of care in the medical practice and that, more generally, doctors' evaluations tend to exhibit excessive optimism. ${ }^{232}$ The authors conclude that "[i]n any case in which a disputed question calls for expert testimony about ordinary practice, it is hazardous to rely on what particular experts recall, and far more sensible to make the outcome turn on statistical evidence, at least if the goal is accuracy in adjudication." 233

Although medical experts might be able to make better sense of the data than juries or judges, any proposal to transfer the direct threat decision to expert panels should be accompanied by the statistical benchmarks reform in order to reduce the likelihood that the experts will make the same errors as ordinary decision makers.

Proposal Four: Comprehensive Grids. This is the most drastic means by which to implement statistical benchmarks but also the most comprehensive policy. This proposal would institute predetermined and quantified risk determinations, such as an actuarial-like table laying out a number representing the risk for most typical plaintiff/disability/workplace combinations.

Rather than supplying a simple bounded scale or a single modulus by which to discipline juries' probability inquiries, this proposal would drastically reduce if not eliminate the role of the jury. Instead, judges or an administrative review board would consider the factors relevant to the particular case at hand, situate the case on the grid, possibly incorporate other unique factors not accounted for by the grid, ${ }^{234}$ and render a determination of whether the plaintiff poses a direct threat.

In sum, although there is obviously significant room for debate over what the benchmarks should be, ${ }^{235}$ and over how they should be

230. See supra note 153 and accompanying text.

231. See Meadow \& Sunstein, supra note 46.

232. Id.

233. Id. at 8-9.

234. This would be in the form of a downward or upward departure.

235. "[A]gencies have quite different standards for deciding when risks are large enough to require any regulation at all. ... The NRC sees 1 in a 1000 as acceptable; the EPA's acceptable range varies from 1 in 10,000 to 1 in 1 million. The FDA has tried to use a standard of 1 in 1 million, but under the 
incorporated into the current framework, the hope is that readers can agree that we should adopt some statistical benchmarks without necessarily having to agree on their exact form.

\section{Statistical Benchmarks, Consistency, and Accuracy}

Statistical benchmarks would address undesirable errors resulting from heuristic devices, the modulus problem, outcome-dependent probability weighting, and the tendency to focus on worst-case scenarios by creating an objective standard that decision makers could use, and rely upon, when determining whether a given individual poses a significant risk. ${ }^{236}$ Statistical benchmarks would introduce coherence to direct threat determinations by requiring decision makers to refer to predetermined rules categorizing risks as significant, insignificant, or somewhere in between. ${ }^{237}$

Statistics, whether in the form of simple numbers, bounded scales, or comprehensive grids, would address the modulus problem by translating the current unanchored determination into a mode that elicits less noisy information from decision makers. Any of the proposals discussed in the previous section would take advantage of what juries might be able to do well and avoid forcing juries to undertake those tasks that they perform poorly. Given that we know juries may have a difficult time mapping their intuitions about risk onto an unbounded scale without a modulus, any proposal requiring juries to map their intuitions onto a bounded scale that specifies standard values for what counts as significant would almost surely improve the consistency and accuracy of the inquiry.

Statistics would also address the problem of outcome-dependent

Delaney Clause, courts have required a standard of essentially zero. OSHA's understanding of the 'significant risk' requirement means a risk of 1 in 1000; labor groups have sought an increase to 1 in 1 million." StePhen G. BReyer et al., Administrative Law and Regulatory Policy: Problems, TEXT, AND CASES 317 (4th ed. 1999) (citations omitted).

236. For an argument in favor of quantifying the significant risk inquiry in the context of EPA regulatory decisions under the Clean Air Act, see Cass $\mathrm{R}$. Sunstein, Is the Clean Air Act Unconstitutional?, 98 MICH. L. REV. 303, 380 (1999) (arguing that the EPA "should explain, as quantitatively as possible, what must be shown in order for a risk to qualify, or not to qualify, as substantial") (emphasis added).

237. Explicit calculation of probabilities will more often than not lead the trier of fact to a more accurate conclusion than will reliance on intuitions and rules of thumb. See Michael Saks \& Robert Kidd, Human Information Processing and Adjudication: Trial by Heuristics, 15 LAW \& Soc. REV. 123, 125 (1980-1981).

The case for numerical benchmarks to discipline the ADA's significant risk inquiry, assuming such benchmarks improve the accuracy and consistency of the decision making process, is particularly compelling when one considers the quantity and diversity of ADA cases in which such an inquiry becomes relevant. "The case for clear standards is strongest... [when] an agency must decide a wide range of cases. In such situations, standardlessness is unacceptable-it creates a recipe for abuse, producing unequal treatment of the similarly situated." Sunstein, supra note 236, at 368 (citing JERRY L. MASHAW, BuREAUCRATIC JuSTICE (1983)). 
probability weighting. By requiring juries to analyze both outcome and probability explicitly, or by implementing a comprehensive grid taking sufficient account for probability, we could very likely reduce the harms resulting from inconsistent sensitivity to probability. We might favor incorporating statistical benchmarks into the direct threat framework on the grounds that the law requires decision makers to pay attention to, and take account of, probability. This is not to say that probability should factor into all decisions, the point is simply that when the legal system requires decision makers to consider probability, and when decisions such as the direct threat determination involve emotion-laden outcomes, the legal system should take a more technocratic approach, specifying requisite probabilities. Because people are likely to discard probability in cases of emotion-laden outcomes, and because the ADA prefers that they carefully consider probabilities, imposing statistical benchmarks or relying on predetermined grids might yield outcomes more consistent with the ADA's ultimate goal.

Statistics would also reduce decision makers' reliance on worst-case scenarios. Currently, individuals considering whether a plaintiff poses a direct threat are likely to overweight low-probability outcomes and underweight high-probability outcomes. Any statistical benchmarks proposal, by making the probability inquiry more transparent and explicit, would help counteract this bias. A comprehensive grid would go even further toward solving the problem by predetermining the requisite probability level needed to find a given risk significant. Because "fear of the worst-case scenario is not as consequential a factor when a single risk source presents differing risk estimates," ${ }^{238}$ even a grid providing significant room for discretion might improve consistency and accuracy.

Statistics have additional advantages. First, benchmarks would contribute to transparency and accountability by forcing juries and judges to justify their decisions with reference to numerical anchors. Benchmarks would force decision makers to justify significant risk findings based on a particular standard rather than reference to an "all things considered" judgment. In this way, benchmarks would enhance the accountability of direct threat decision makers.

Second, benchmarks that ultimately preserve the role of the judge and jury may have dynamic effects on the arguments presented by plaintiffs and defendants. On this account, the use of benchmarks contributes to rule of law values. Benchmarks would allow more intelligent challenges to the EEOC's failure to take a given case and they would provide an intelligible basis for lawsuits and appeals by private plaintiffs. Similarly, benchmarks would provide guidance and notice to employers seeking to structure their

238. See Viscusi, supra note 193 , at 1668 . 
behavior in accordance with the law. All of the relevant parties would be in a better position to assess the merits of their respective claims and to conform their behavior to the law.

Furthermore, an inquiry disciplined by numerical benchmarks would better advance the ADA's purpose. One purpose of the ADA is to address "a history of purposeful unequal treatment," "overprotective rules and policies," and "stereotypic assumptions" about the disabled. ${ }^{239}$ We might favor an interpretation of direct threat that requires statistical inquiry and eschews open-ended judge or jury determinations that might be prone to the same stereotypes the ADA seeks to eliminate. ${ }^{240}$ The inaccuracy and inconsistency evidenced by the HIV and psychiatric disability cases demonstrates the diminished ability of an unanchored framework to combat discrimination, at least for some categories of the disabled.

Another goal of the ADA is "to provide a clear and comprehensive national mandate for the elimination of discrimination against individuals with disabilities" and to "provide clear, strong, consistent, enforceable standards." 241 Statistical benchmarks would better serve this goal than the existing "I know a significant risk when I see one" approach. A statistically disciplined inquiry would address the ADA's goal of consistent standards by aligning direct threat determinations across similarly situated plaintiffs and across categories of disabilities.

Finally, although statistical benchmarks would not necessarily eliminate juries from the equation, benchmarks would clearly reduce juries' discretion. Benchmarks would limit opportunities for both invidious discrimination and error-producing heuristics to contaminate the analysis. If reducing juries' discretion contributes to more accurate and consistent decision making then a policy that reduces jury discretion can be justified on the rationale that it advances the ADA's purpose. Benchmarks would also address the concern that juries only see cases one at a time whereas successful risk management requires looking at the bigger picture. ${ }^{242}$ The benchmarks, by introducing some element of consistency across categories, could help situate ADA direct threat decisions amongst themselves and

239. 42 U.S.C. § 12101(a)(2)-(7).

240. When assessing whether an individual poses a direct threat, and evaluating the relevant evidence, "courts must be mindful of the ADA's express goal of eliminating discrimination against people with disabilities." Bay Area Addiction Research and Treatment, Inc. v. City of Antioch, 179 F.3d 725, 736-37 (9th Cir. 1999) (recognizing that courts should beware of making significant risk determinations based on unfounded fears of the disabled, but conducting an open-ended inquiry of whether plaintiff drug addicts would pose a direct threat to the community based on a "reasonable likelihood of a significant increase in crime").

241. 42 U.S.C. $\$ 12101$ (b)(1)-(2) (emphasis added).

242. See Hastie \& Viscusi, supra note 61, at 902 ("[A]lthough an effective risk management policy is founded on the detailed analysis of individual cases . . . it requires an omnibus consideration of the distribution of cases, probabilities, benefits, and costs."). 
amongst other risk-related cost/benefit determinations. In this way, statistical benchmarks could actually empower juries by facilitating decisions more in line with the decisions those juries would make were they fully informed.

\section{Feasibility of Statistical Benchmarks}

One possible objection to the use of statistical benchmarks is that such benchmarks would be difficult to generate and utilize because reliable data is lacking. The direct threat inquiry would be no more accurate, so the argument goes, because it would be based on statistics that are no less arbitrary then the current bases for decisions.

But it is reasonable to expect defendants to present significant risk defenses complete with numbers relevant to the probability of the alleged harm coming to fruition. Under existing doctrine, employers asserting the direct threat defense already must gather "substantial information' about the employee's work history and medical status" and not rely on "subjective evaluations." 243 Parties equipped with this "substantial information" could, without significant logistical difficulties, provide statistics relevant to probability in order to inform the inquiry in light of enumerated benchmarks. Bragdon requires courts to give the views of public health authorities "special weight and authority." 244 Public health data, already in existence, could be harnessed as a source of evidence relating to the significance of a given risk. Those challenging the conventional numbers supplied by public health authorities could use the statistical anchors as objective benchmarks useful to analyzing the conclusions one should draw from public health data.

In addition, a substantial pool of risk data already exists. ${ }^{245}$ A plethora of actuarial data sets provide solid evidence about the risks posed by individual jobs and workplaces. ${ }^{246} \mathrm{~A}$ specific example of comprehensive quantification is a recent EPA effort to assign dollar values to a host of health harms short of death. The EPA determined that chronic bronchitis was worth $\$ 260,000$, congestive heart failure was worth $\$ 20,600$ for people under 65 , an emergency room visit was worth $\$ 9,000$, and a single episode of shortness of breath was worth $\$ 5.30 .^{247}$ The existence of such data bears

243. Nunes v. Wal-Mart Stores, Inc., 164 F.3d 1243, 1248 (9th Cir. 1999); see Bragdon v. Abbott, 524 U.S. 624,649 (1998) (noting that defendants may not rely on subjective evaluations of the threat allegedly posed by plaintiff); Mantolete v. Bolger, 767 F.2d 1416, 1423 (9th Cir. 1985) (noting the substantial information requirement under the Rehabilitation Act).

244. Bragdon, 524 U.S. at 650.

245. See supra note 46.

246. VISCUSI, supra note 60 , at 56.

247. See U.S. EPA Innovative Strategies \& Economics Group, Office of Air Quality Planning \& 
favorably on the EEOC's ability to develop meaningful benchmarks and litigants' ability to make use of them. If it is difficult to quantify the relevant variables, but necessary to do so in order to advance the ADA's antidiscriminatory aim, then this simply argues for the EEOC devoting resources to doing so.

In response to a similar criticism levied against the proposal that the EPA, to better discipline its standard setting, should develop statistical measures of pollution level reduction "requisite to protect the public health" ${ }^{248}$ under the Clean Air Act, ${ }^{249}$ Judge Williams argued that we make such complex calculations all the time and that such calculations are likely within the competence of agencies, especially given government experience with the use of Quality-Adjusted Life Years (QUALYs): ${ }^{250}$

All the relevant variables seem to range continuously from high to low: the possible effects of pollutants vary from death to trivialities, and the size of the affected population, the probability of an effect, and the associated uncertainty range from "large" numbers of persons with point estimates of high probability, to small numbers and vague ranges of probability. This does not seem insurmountable. Everyday life compels us all to make decisions balancing remote but severe harms against a probability distribution of benefits .... [A]n agency wielding [substantial] power over American life ... should be capable of developing the rough equivalent of a generic unit of harm that takes into account populations affected, severity and probability. Possible building blocks for such a principled structure might be found in the approach Oregon used in devising its health plan for the poor.... Oregon ranked treatments by ... improvement in "QualityAdjusted Life years." ${ }^{251}$

Additionally, society's increasing ability to calculate risk ${ }^{252}$ lends further credence to the notion that the quantification problem is likely diminishing and will continue to do so. ${ }^{253}$ Experts at the Harvard Center for Risk Analysis note that "[i]n many areas, science can identify the physical hazards, tell us how many people are likely to be affected by each one, what various mitigations will cost and how effective we can expect them to be.

Standards, Regulatory Impact Analyses for the Particulate Matter and Ozone National Ambient Air Quality Standards and Proposed Regional Haze Rule 12-43 (1997).

248. 42 U.S.C. $\$ 7409$ (b)(1).

249. 42 U.S.C. $\$ 7401$ et seq. (1994).

250. See Richard H. Pildes \& Cass R. Sunstein, Reinventing the Regulatory State, 62 U. Chi. L. Rev. 1, 73-86 (1995) (discussing QUALYs); see also infra Part V.C.4 (discussing the potential of QUALYs to form a comprehensive framework for ADA risk assessment).

251. American Trucking Assoc. v. EPA, 175 F.3d 1027, 1039 (D.C. Cir. 1999), aff'd in part, rev'd in part, and rem'd sub nom., Whitman v. American Trucking Assoc., Inc., 121 S. Ct. 903 (2001).

252. "As science advances and our ability to detect risks improves, our opportunities for influencing risks have proliferated." VISCUSI, FATAL TRADEOFFS, supra note 60, at 158.

253. See supra note 46. 
We can rank risks and remedies and put things in perspective."254

Finally, even if benchmarks cannot be established with statistical perfection, many of the advantages to their use are not lost. Solving the modulus problem, reducing outcome-dependent probability weighting, and preventing reliance on worst-case scenarios can be accomplished by even partially accurate benchmarks; so long as they serve as some basis to guide the inquiry they are likely more effective than sailing further adrift in the existing significant risk sea. It would be better to begin the significant risk inquiry with solid yet imperfect statistics than with decision makers' misguided intuitions.

\section{Toward a Comprehensive Decision Making Framework}

The size of the affected population and the magnitude of the potential harm are two important variables in calculating whether a risk is significant. ${ }^{255}$ A meaningful comparison of a $1 / 1,000$ risk versus a one in one million risk, for example, requires some way to standardize these probability judgments to account for different magnitudes of harm and different sizes of populations at risk. Probability in a vacuum does not tell us very much.

This observation leads to a sensible objection to statistical benchmarks that discipline only the probability inquiry. Under this proposal, one can imagine decision makers getting probability right but, in determining whether the overall risk counts as significant, still getting the answer wrong. Decision makers, provided with benchmarks indicating that $1 / 1,000$ is a presumptively significant probability and one in one million is presumptively insignificant, would still not know whether the overall risk under consideration was significant without information regarding the magnitude of the potential harm. Similarly, disciplining the probability inquiry might still leave the overall decision unguided if the magnitude of potential harm and affected population variables remain unguided. A $1 / 1,000$ risk of a broken arm, for example, is less significant than a $1 / 1,000$ risk of death, but how much less significant? The probability benchmarks, while useful, do not aid decision makers who must answer this question. A $1 / 1,000$ risk of a single death is less significant than a $1 / 1,000$ risk of a hundred or a million deaths, but, again, probability. benchmarks do not discipline this comparison. On this account, statistical benchmarks to discipline the probability inquiry still leave the overall significant risk decision unguided-the inconsistency and inaccuracy problems will persist.

254. Ropeik, supra note 54, at B4.

255. See HAMIITON \& VISCUSI, supra note 196, at 91-108 (explaining the importance of considering the size of the at risk population). 
In order to address this objection, we might combine numerical benchmarks indicating what counts as a presumptively significant (or insignificant) probability with a second set of benchmarks for what counts as significant (or insignificant) harm. For instance, a benchmark indicating that a $1 / 1,000$ probability is presumptively significant could be combined with a benchmark indicating that, for example, one death or a broken leg is a presumptively significant harm. The combination would result in a more global benchmark, indicating that a $1 / 1,000$ risk of one death, for example, is a presumptively significant risk. Such a global benchmark could then be generalized across countless permutations in order to discipline the significant risk inquiry in all circumstances. A harm of ten deaths might require a risk of only $1 / 10,000$ to count as presumptively significant. Likewise, a harm of a single hospitalization, or a single lost workday, might require a probability as high as $1 / 100$ to count as significant. Harms such as lost workdays, hospitalizations, cancer, and respiratory dysfunction can all be quantified. ${ }^{256}$ By adjusting the probability benchmarks to account for harms of different magnitudes and to account for harms affecting various population sizes, a disciplined significant risk inquiry, accounting for the relevant variables (probability, harm, and size of a risk population), would emerge.

QUALYs facilitate creation of a global benchmark accounting for probability, harm, and size of the at risk population. ${ }^{257}$ A QUALY is a unit of health measurement based on subjects' attitudes toward various states of health. By providing a standard measurement of health conditions, the QUALY allows decision makers to compare across categories of health harms that may seem, at first cut, incommensurate. For instance, by providing information regarding individuals' subjective dislike for respiratory problems, cancer, death, and countless other health harms, QUALYs allow decision makers to evaluate how much "worse" cancer is than, for example, asthma. The QUALY unit of measuremert could allow decision makers, in the context of the ADA, to standardize the inquiry (into magnitude of harm and size of population at risk) by converting the relevant variables into a single unit of potential harm measured in terms of life years

256. See, e.g., Sunstein, supra note 236 , at app. tbl. 2. See also supra note 247 and accompanying text.

257. See American Trucking Ass'n., 175 F.3d at 1039-40 \& n.5 (advocating EPA use of QUALYs); see also Sunstein, supra note 236, at $320 \& \mathrm{n} .73,348$ (explaining the use of QUALYs to produce a "global figure... to quantify the various benefits from regulation"); Robert Fabian, The Qualy Approach, in VAluing HeALTH FOR POLICY: AN ECONOMIC APPROACH 118 (George Tolley et al. eds., 1994); George W. Torrance, Measurement of Health State Utilities for Economic Appraisal: A Review, 5 J. HeAlth Econ. 1 (1986); Robert M. Kaplan \& James W. Bush, Health-Related Quality of Life Measurement of Evaluation and Policy Analysis, 1 HEALTH PSYCH. 61 (1982); Richard Zeckhauser \& Donald Shepard, Where Now for Saving Lives?, 40 LAw \& CONTEMP. PROBS. 5, 5, 11 (Autumn 1976) (first describing the QUALY unit of measurement). 
at risk.

Numerical benchmarks, to discipline the probability inquiry, could serve as a platform for implementing a QUALY-based approach. An approach based on QUALYs would utilize probability benchmarks and combine them with a specified QUALY measurement, to form a more global benchmark stating that, for example, a 1/1,000 risk of losing twentyfive QUALYs is a presumptively significant risk. Harms affecting differently sized populations and harms of different magnitudes would, in this way, be translated into QUALYs to determine whether they met the overall significance threshold.

Empirical support for the use of QUALYs makes such an approach even more appealing. Oregon, for example, has used QUALYs to assess health gains for the purposes of creating a health plan for the poor. ${ }^{258}$ Perhaps an approach similar to that used by Oregon could be used by decision makers attempting to calculate overall health risks posed by disabled individuals in the workplace.

Finally, there may be some value to disciplining the probability inquiry even if the magnitude of the potential harm inquiry remains unanchored. By pinning down the probability inquiry, at least one element of the overall significance determination is disciplined. The overall accuracy and consistency can be expected to improve even if only one of several variables is assessed more rigorously. In addition, disciplining only the probability variable may do more to improve the accuracy and consistency of the overall significant risk inquiry than we might suspect at first glance. This is especially true if the probability inquiry is uniquely vulnerable to inaccurate heuristics or discriminatory bias as the preceding discussion suggests. ${ }^{259}$ Disciplining the probability inquiry alone might have an effect similar to fixing the one weak leg of a chair, improving the overall stability of the significant risk inquiry. On this account, improving the accuracy of only one third of the significant risk inquiry might have a disproportionately stabilizing affect on the overall decision making process.

\section{VI. \\ CONCLUSION}

One defense to alleged discrimination under the ADA is that the plaintiff would pose a direct threat to the health or safety of others. The ADA defines a direct threat as a significant risk. Current direct threat determinations, attempting to operationalize significant risk, are both inconsistent and inaccurate. The result is that some disabled individuals are

258. See supra text accompanying note 251 .

259. See infra Part IV. 
wrongfully excluded from the workplace and that others are mistakenly permitted to work at great risk to themselves and others.

Numerical benchmarks should be used to improve the consistency and accuracy of direct threat determinations. Decision makers should make significance determinations aided by statistics that provide some modulus by which to measure whether a risk is clearly significant, cle rrly insignificant, or somewhere in between. The EEOC should adopt explicit benchmarks, looking to the statistical benchmarks used by OSHA to serve as a guide for when a risk is sufficiently large to be considered "significant." These benchmarks would result in more consistent and accurate determinations under the ADA which, in turn, would advance the statute's antidiscriminatory purpose. 
THIS PAGE INTENTIONALLY LEFT BLANK. 